\title{
Institutions, Corporate Governance and Capital Flows
}

\author{
Rahul Mukherjee \\ Graduate Institute of International and Development Studies
}

\begin{abstract}
Countries with weaker domestic institutions hold fewer foreign assets and exhibit concentrated corporate ownership. An equilibrium business cycle model of international capital flows with corporate governance frictions between outside investors and insiders explains both phenomena. Investment dynamics under insider control leads relative dividend and labor income for outsiders to be more negatively correlated in countries with weaker institutions. Consequently, outsiders hold more domestic assets to hedge labor income risk. I provide empirical evidence on this hedging demand. Concentrated ownership arises because international diversification through the sale of domestic assets by insiders is penalized by lower stock market valuation.
\end{abstract}

(C) The Authors.

All rights reserved. No part of this paper may be reproduced without the permission of the authors. 


\title{
Institutions, Corporate Governance and Capital Flows*
}

\author{
Rahul Mukherjee \\ May 17, 2013
}

\begin{abstract}
Countries with weaker domestic institutions hold fewer foreign assets and exhibit concentrated corporate ownership. An equilibrium business cycle model of international capital flows with corporate governance frictions between outside investors and insiders explains both phenomena. Investment dynamics under insider control leads relative dividend and labor income for outsiders to be more negatively correlated in countries with weaker institutions. Consequently, outsiders hold more domestic assets to hedge labor income risk. I provide empirical evidence on this hedging demand. Concentrated ownership arises because international diversification through the sale of domestic assets by insiders is penalized by lower stock market valuation.
\end{abstract}

Keywords: Home bias, institutional quality, corporate governance

JEL Codes: F21, F41, G15

*Acknowledgements: An earlier draft of this paper circulated as Country Portfolios with Imperfect Corporate Governance. I am indebted to Linda Tesar, Uday Rajan, Jing Zhang and Andrei Levchenko for their encouragement, time and advice. Additional thanks to: Heitor Almeida, Ron Alquist, Philippe Bacchetta, Rüdiger Bachmann, Nicolas Couerdacier, Gita Gopinath, Pierre-Olivier Gourinchas, Sergei Guriev, Harald Hau, Mathias Hoffmann, Jean Imbs, Beata Javorcik, Logan Lewis, Raoul Minetti, Francesc Ortega, Thomas Piketty, Romain Rancière, Roberto Rigobon, Cédric Tille, Neng Wang and conference/seminar participants at EEA-ESEM, CEF, Infiniti, T2M, University of Geneva, Delhi School of Economics, HEC Lausanne, Midwest Macro Meetings, Paris School of Economics, IHEID, and the University of Michigan for comments. All remaining errors are mine.

${ }^{\dagger}$ Correspondence: Department of Economics, Graduate Institute of International and Development Studies, Avenue de la Paix 11A, 1202 Genève, Switzerland. Mail: rahul.mukherjee@graduateinstitute.ch. Web: https://sites.google.com/site/rahulmkiheid/ 


\section{Introduction}

Institutions, which cover a broad spectrum of economic arrangements such as courts of law, corporate governance standards and the quality of contract enforcement, have recently received much attention as determinants of economic performance. Yet, how institutions influence international capital flows is neither well documented nor understood. This paper fills this gap in three ways. First, it uncovers a novel stylized fact about the well-known equity home bias puzzle concerning international capital flows - I find that countries with lower institutional quality ("the South") also hold fewer foreign assets. ${ }^{1}$ This appears counter-intuitive. Why would countries with worse domestic institutions be more home-biased in their equity holdings, while having apparently better alternatives in countries with better institutions ("the North")? The second, and central, contribution of this paper is to show theoretically that this striking pattern might actually be an equilibrium outcome of the interaction between agency problems and weaker institutions in the South. The third and final contribution of the paper is to provide cross-country evidence about the macroeconomic mechanism underlying these stylized facts and theoretical results.

To better understand the crucial role of agency problems in shaping capital flows, I start with the observation that equity in firms is typically held by two distinct economic actors, outsiders and insiders. An outsider is a small investor who owns stock in a firm but has no direct control over its operations. The majority of her income comes from supplying labor. In short, she fits the description of the classical atomistic agent in a business cycle model. By contrast, an insider is a large shareholder who has control over the investment, dividend, and employment policies of a firm by virtue of her sizeable equity stake. Weaker institutions lower the ability of outsiders to hold insiders accountable for their decisions through the usual mechanisms of corporate governance.

With this story in mind, I develop a two-country dynamic stochastic general equilibrium model of international portfolio choice with two distinct agents in each country - an outsider and an insider. I incorporate the conflict of interest that arises between these two parties when the latter has full control of the firm, yet owns only a part of it. Weaker institutions, by opening up opportunities for self-interested behavior by insiders, affect the payoffs of claims to the firm's dividends. This influences the portfolio choice of both outsiders and insiders, yielding two main results. First, I find that for a given size of the float portfolio, ${ }^{2}$ domestic outsiders will exhibit greater home bias in asset holdings in countries with weaker institutions. Second, in addition to this, worse institutions will make the domestic float portfolio itself smaller. The aggregate home bias in each country will then be the sum of these two elements.

The first result, that Southern outsiders are more home biased for a given float portfolio,

\footnotetext{
${ }^{1}$ This remains true, as I show later, both for assets and liabilities, after accounting for controls such as capital flow restrictions. Institutional quality is measured by the indices from LaPorta et al. (1998) and Kaufmann et al. (2008).

${ }^{2}$ The float portfolio is a term used to describe the fraction of a country's stock market that is actively traded in international equity markets, and is equal to the part not held by insiders.
} 
follows from the impact of imperfect corporate governance on the ability of domestic assets to hedge labor income risk. The hedging properties of domestic assets have been examined as a possible explanation of home bias by Cole and Obstfeld (1991), Baxter and Jermann (1997), van Wincoop and Warnock (2010), Coeurdacier et al. (2010), Heathcote and Perri (2009), and Coeurdacier and Gourinchas (2012), among others. Building especially on the last two I show that imperfect corporate governance, by influencing the second moments of domestic assets, makes them a better hedge against labor income risk in countries with worse institutions. The underlying mechanism, working primarily through the insiders' decisions about the dynamics of investment, draws on an extensive literature in financial economics (see LaPorta et al., 2000b; Nenova, 2003; Dyck and Zingales, 2004) showing that insiders in the South can extract rents from firms as private benefits of control. Since more rents can be extracted from larger firms, insiders effectively become empire-builders. ${ }^{3}$

Consider the case of a positive productivity shock. Empire-building affects the resultant dynamics of investment in the following way. When hit by a persistent positive productivity shock, insiders in the South find it privately optimal to reduce dividends below the first-best level to finance socially suboptimal capital investments in expectation of higher future private benefits. As a result dividends shrink relative to the North. At the same time, the shock tends to increase labor income in the South, relative to the North. Thus imperfect corporate governance amplifies the negative correlation between relative dividends and relative labor earnings in the South. Consequently, home bias for domestic outside investors is greater in the South, due to their increased demand for domestic shares for the purpose of hedging their labor income risk. In general equilibrium, this also leads to lower Northern ownership of the Southern float portfolio, and more home bias in the North.

The second result, that the South also has greater insider ownership of firms, and hence, a smaller float portfolio, works through a channel that has been studied by Admati et al. (1994) and DeMarzo and Urošević (2006) in partial equilibrium models. As noted earlier, weaker institutions in the South let domestic insiders extract private benefits of control. Lower insider equity, by reducing the insider's ownership of cash-flow rights of the firm, increases extraction. Thus, riskaverse Southern insiders, wishing to diversify country-specific risk by buying foreign assets, can only sell their stake at a discount; outside investors, anticipating greater extraction, are only willing to trade shares with the insider at a lower price corresponding to the lower post-trade level of insider ownership. This acts as an endogenous "transaction tax" on the insider's portfolio adjustments. The insider's trade-off, between the potential benefits of diversification and the penalty of the transaction tax, determines the size of the float portfolio of a country. Since the

\footnotetext{
${ }^{3}$ This is a version of the free-cash flow problem first pointed out by Jensen (1986). Private benefits of control could vary from outright pilferage of firm assets, to more subtle forms like product discounts to subsidiaries and share sales at low prices to related parties. See Nenova (2003), Dyck and Zingales (2004), and Albuquerque and Schroth (2010) for empirical estimates of private benefits, and Albuquerque and Wang (2008) for cross-country evidence on over-investment.
} 
effect of the transaction tax dominates in the Southern equilibrium, it ends up with more insider ownership. This outcome can be thought of as home bias on the part of insiders.

Since the seminal work of Acemoglu et al. (2002), the quality of institutions is seen as a critical determinant of macroeconomic outcomes such as long term growth (Sevcik, 2012; Castro et al., 2004), and financial development (LaPorta et al., 1997, 1998). In this paper, I focus on a sharply defined aspect of institutions, namely investor protection laws and their implementation, and their link to the macroeconomics of international capital flows. While private benefits of control and the agency problems associated with insider ownership have long been central to the finance literature, these have not yet been incorporated into international macroeconomics. ${ }^{4}$ To the best of my knowledge, this paper presents the first international real business cycle model with endogenous labor income and asset returns that characterizes the international portfolios of countries with heterogenous institutions in the presence of agency problems. Thus, I bring together two areas in international macroeconomics and finance that have, surprisingly, remained separate until now.

The main theoretical innovation of this paper lies in showing how poor institutions may amplify the effects of a well-known candidate explanation of home bias, non-diversifiable labor income risk. For this, I draw on insights from two lines of research. The first is the literature concerning the implications of agency problems on asset-pricing (Dow et al., 2005; Albuquerque and Wang, 2006, 2008) and macroeconomic aggregates (Danthine and Donaldson, forthcoming; Philippon, 2006). My results address international portfolio allocation in the backdrop of this literature. The second is the recent work of Heathcote and Perri (2009) and Coeurdacier et al. (2010) that has focused on the interaction of trade openness and labor income risk to explain the home bias puzzle. In contrast, I emphasize a different channel, institutional quality, through which labor income risk determines home bias.

Empirically, the contribution of this paper is twofold. Building on Faria et al. (2007) and Faria and Mauro (2009), it uncovers a new stylized fact about institutions and international asset holdings. It also provides empirical evidence on the main theoretical mechanism about aggregate second moments described in the paper, adding to the growing evidence on the correlation between asset and labor income (among others, Coeurdacier and Gourinchas, 2012; di Giovanni and Matsumoto, 2012).

My work is also complementary to the extensive literature on capital flows in the presence of financial frictions, exemplified by the work of Mendoza et al. (2009), Antras and Caballero (2009), Kraay et al. (2005), Kalemli-Ozcan et al. (2008), Broner and Ventura (2010, 2011), to name just a few. The papers most closely related to my work are Heathcote and Perri (2009), Albuquerque and Wang (2006, 2008), and Coeurdacier and Gourinchas (2012). I discuss the connections between my results and theirs in more detail in a later section.

\footnotetext{
${ }^{4}$ Albuquerque and Wang (2006) is a notable exception. Also see LaPorta et al. (1998, 1999, 2000a,b, 2002), Shleifer and Wolfenzon (2002), Nenova (2003), Dyck and Zingales (2004), Dahlquist et al. (2003), Kho et al. (2009).
} 
The rest of the paper is organized as follows. Section 2 establishes a new empirical regularity about the cross section of country portfolios and reviews some that are well-known. Section 3 lays out a dynamic model of portfolio choice by outsider investors with exogenous insider ownership. Section 4 presents the main results of the paper and provides intuition for them. Section 5 tests the main theoretical mechanism in a cross section of countries. Section 6 discusses an extension with endogenous insider ownership. Section 7 concludes.

\section{Stylized Facts}
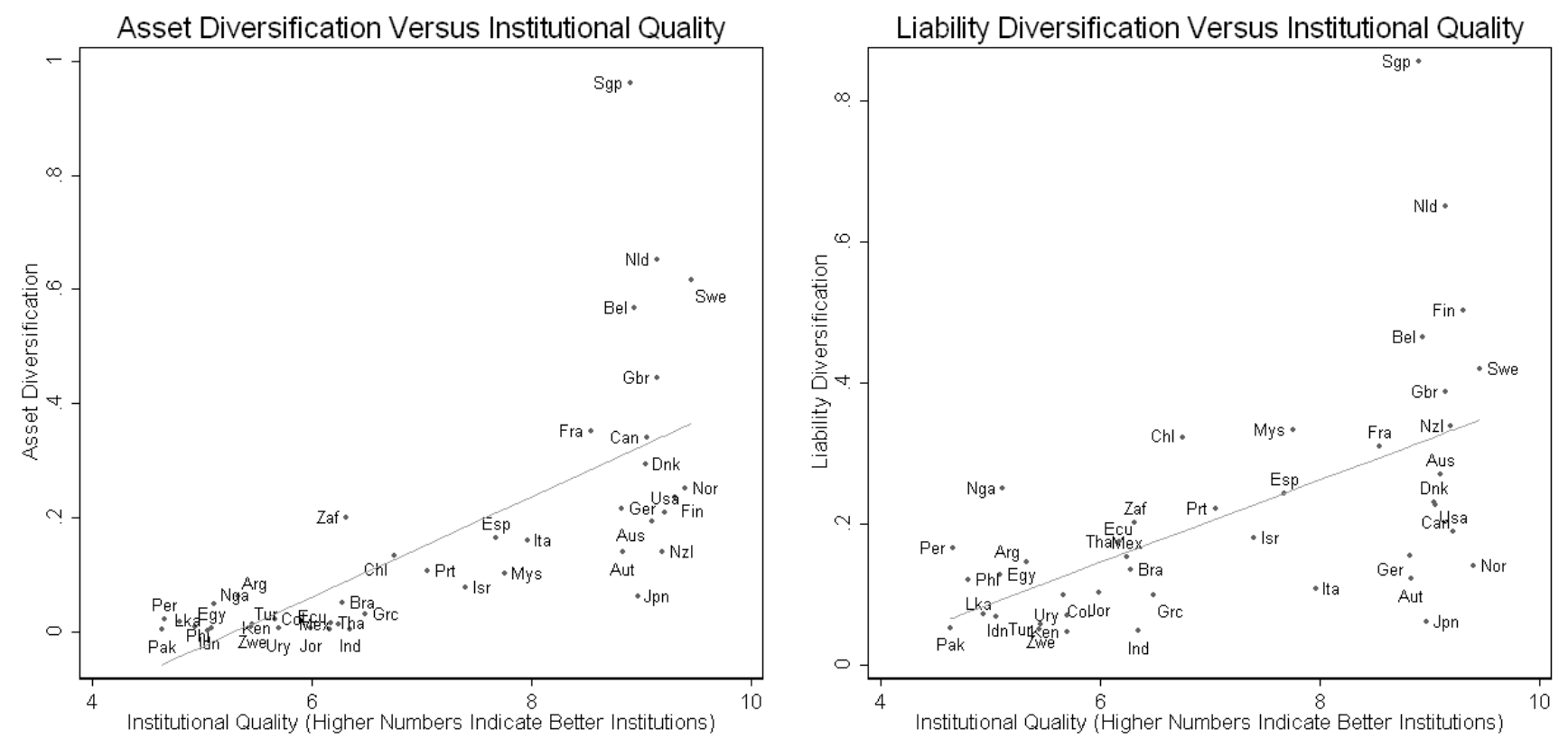

Figure 1: INSTITUTIONS AND DIVERSIFICATION

Notes: Each point represents the time average (1996-2004) for each country. Institutional quality measured by the LaPorta et al. (1998) indices on the x-axis. The ratio of foreign equity assets (liabilities) to GDP in panel 1 (2) on the y-axis. Data source: Lane and Milesi-Ferretti (2007) and LaPorta et al. (1998).

Figure 1 draws scatter plots with institutional quality on the horizontal axis and two measures of international diversification on the vertical axis for a group of 43 countries (21 developed markets, 22 emerging markets). ${ }^{5}$ 'Institutional quality' is a simple average of indices from LaPorta et al. (1998) that measure the rule of law, risk of contract repudiation and expropriation, accounting standards, and efficacy of the judicial system. The picture remain unchanged when using a more

\footnotetext{
${ }^{5}$ Since the theoretical mechanism in the model is likely to be important only for countries making significant use of external finance for firms, I use the sample of LaPorta et al. (1999) with a few modifications. Specifically, I include countries that had at least 5 domestic non-financial publicly traded firms with no government ownership in 1993. I exclude Luxembourg, Ireland and Switzerland from the analysis because their gross external positions are unusually large in relation to their GDP due to their status as financial centers. The countries are listed in the appendices.
} 
general measure of a country's institutions, like the Kaufmann et al. (2008) indices. ${ }^{6}$ The measures of international diversification are the ratios of foreign assets (and liabilities) to gross domestic product. I focus on portfolio and foreign direct investment as these financial claims have explicit equity attached to them, unlike debt. The world distribution of assets and liabilities suggest that countries with better domestic institutions are also better diversified using greater cross-holdings. ${ }^{7}$
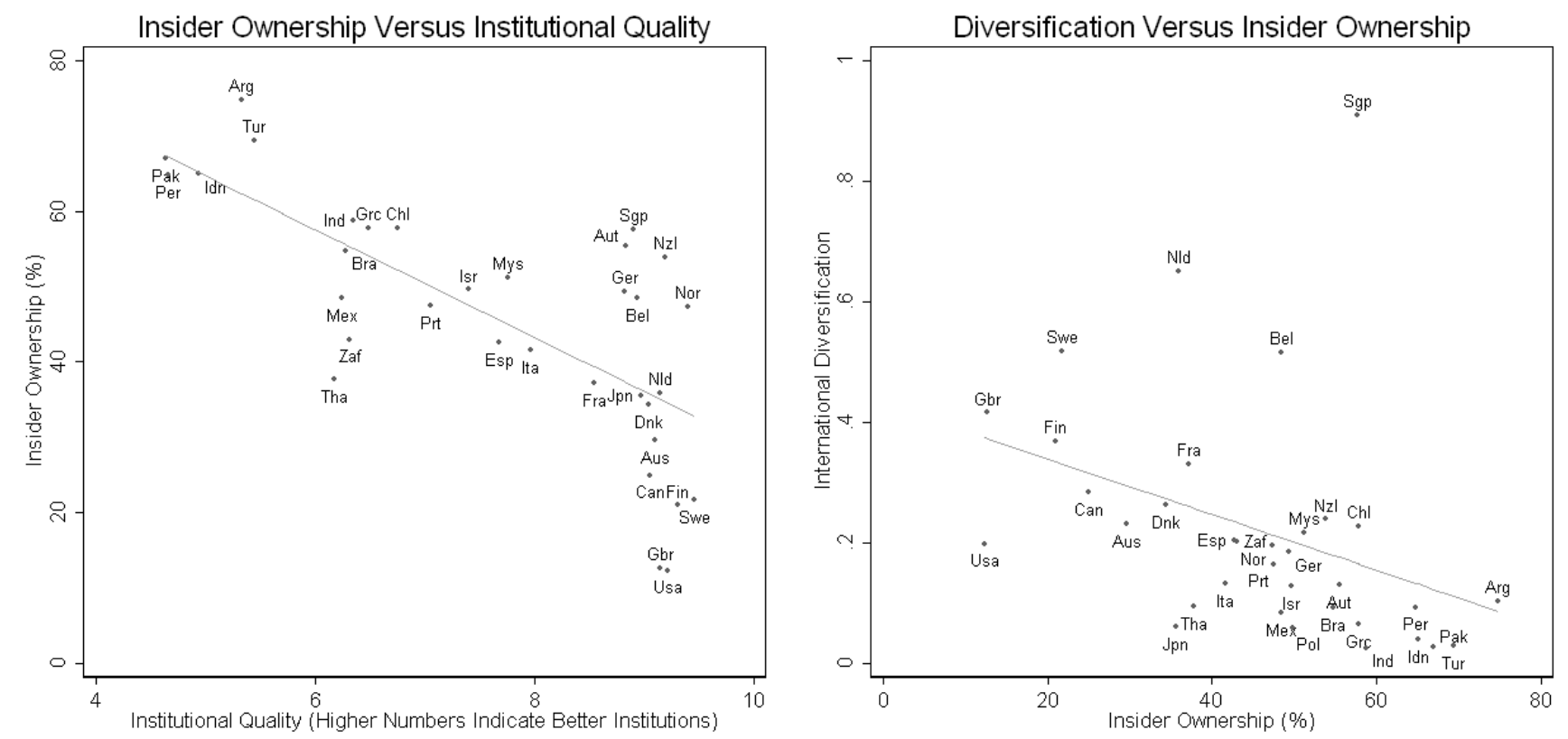

Figure 2: INSTITUTIONS, INSIDER OWNERSHIP AND DIVERSIFICATION Notes: Each point represents the time average (1996-2004) for each country. Institutional quality measured by the LaPorta et al. (1998) indices on the x-axis of panel 1 . The valueweighted average percentage insider ownership in a country's firms on y-axis in panel 1 and x-axis of panel 2. The ratio of foreign equity assets and liabilities to GDP on y-axis in panel 2. Data source: Kho et al. (2009), Lane and Milesi-Ferretti (2007) and LaPorta et al. (1998).

The first panel of Figure 2 plots the percentage of market capitalization of a country closely held, versus institutional quality, using a subset of 34 countries for which insider ownership data has been compiled by Kho et al. (2009). This shows countries having better institutional quality also exhibiting lower insider ownership. The second panel of Figure 2 plots the ratio of foreign equity assets plus liabilities to GDP on the vertical axis versus insider ownership. It makes a point about insider ownership and international risk sharing - the greater the fraction of financial claims on a nation available for outsiders, the more internationally diversified a nation is.

\footnotetext{
${ }^{6}$ I look at the years 1996-2004 because that is the period of overlap of the external wealth measures for the years 1970-2004 from Lane and Milesi-Ferretti (2007) and the institutional quality indices from Kaufmann et al. (2008). The data sources are summarized in the appendices (B.1.1).

${ }^{7}$ OLS regressions with a host of control variables, used later to test some predictions of the model, confirm this assertion.
} 


\section{Benchmark Symmetric Model}

\subsection{Goods and Assets Markets}

There are two countries in the world - North and South. Each country produces an internationally traded intermediate good using capital $(\mathrm{K})$ and labor $(\mathrm{L}) \cdot a\left(s^{t}\right)$ is produced only in the North, and $b\left(s^{t}\right)$ only in the South. ${ }^{8}$ Except for the total output of the intermediate goods in the North and the South, which are denoted by $Y_{a}$ and $Y_{b}$ respectively, all quantities associated with the South are superscripted with a "*”. The production functions for the intermediate goods are

$$
\begin{aligned}
& Y_{a}\left(s^{t}\right)=Z\left(s^{t}\right) K\left(s^{t-1}\right)^{\theta} L\left(s^{t}\right)^{1-\theta} \\
& Y_{b}\left(s^{t}\right)=Z^{*}\left(s^{t}\right) K^{*}\left(s^{t-1}\right)^{\theta} L^{*}\left(s^{t}\right)^{1-\theta}
\end{aligned}
$$

The only source of uncertainty is the technology in the intermediate goods sector of each country, described by the stochastic processes $Z\left(s^{t}\right)$ and $Z^{*}\left(s^{t}\right)$. These evolve according to first-order auto-regressive processes driven by homoscedastic shocks $\epsilon\left(s^{t}\right)$ and $\epsilon^{*}\left(s^{t}\right)$.

$$
\begin{aligned}
\log \left(Z\left(s^{t}\right)\right) & =\rho_{11} \log \left(Z\left(s^{t-1}\right)\right)+\rho_{12} \log \left(Z^{*}\left(s^{t-1}\right)\right)+\epsilon\left(s^{t}\right) \\
\log \left(Z^{*}\left(s^{t}\right)\right) & =\rho_{22} \log \left(Z^{*}\left(s^{t-1}\right)\right)+\rho_{21} \log \left(Z\left(s^{t-1}\right)\right)+\epsilon^{*}\left(s^{t}\right)
\end{aligned}
$$

Both intermediate goods are used in the production of the final consumption-investment good in each country. The two intermediates are combined using a standard CES technology that is not subject to uncertainty

$$
\begin{aligned}
Y\left(s^{t}\right) & =\left[\omega a\left(s^{t}\right)^{\frac{\sigma-1}{\sigma}}+(1-\omega) b\left(s^{t}\right)^{\frac{\sigma-1}{\sigma}}\right]^{\frac{\sigma}{\sigma-1}} \\
Y^{*}\left(s^{t}\right) & =\left[\omega^{*} a^{*}\left(s^{t}\right)^{\frac{\sigma-1}{\sigma}}+\left(1-\omega^{*}\right) b^{*}\left(s^{t}\right)^{\frac{\sigma-1}{\sigma}}\right]^{\frac{\sigma}{\sigma-1}}
\end{aligned}
$$

where $\sigma$ is the elasticity of substitution between foreign and domestic intermediates. $\omega$ and $\omega^{*}$ are assumed to be greater than $\frac{1}{2}$ to reflect an exogenous preference for domestic intermediates.

The real exchange rate between the two countries and North's terms of trade, which are defined as the price of the Southern final good relative to the Northern final good and the ratio of North's

\footnotetext{
${ }^{8}$ At each time $t$, the economy is in state $s_{t} \in \mathbb{S}$, where $\mathbb{S}$ is the set of possible states of the world. The sequence of events from the start of time till date $t$ is denoted by the history $s^{t}$.
} 
import to export price, can be written as,

$$
\begin{aligned}
e\left(s^{t}\right) & =\frac{q_{a}\left(s^{t}\right)}{q_{a}^{*}\left(s^{t}\right)}=\frac{q_{b}\left(s^{t}\right)}{q_{b}^{*}\left(s^{t}\right)} \\
t\left(s^{t}\right) & =\frac{q_{b}\left(s^{t}\right)}{q_{a}\left(s^{t}\right)}
\end{aligned}
$$

by the law of one price for the traded intermediate goods. Defined this way, a depreciation of the real exchange rate or the terms of trade for North is an increase in its algebraic value.

The optimal combination of the two intermediate goods used to produce a given amount of the final good are characterized by the following conditions derived from a cost-minimization problem,

$$
\begin{gathered}
\omega Y\left(s^{t}\right)^{\frac{1}{\sigma}} a\left(s^{t}\right)^{-\frac{1}{\sigma}}=q_{a}\left(s^{t}\right) \\
(1-\omega) Y\left(s^{t}\right)^{\frac{1}{\sigma}} b\left(s^{t}\right)^{-\frac{1}{\sigma}}=q_{b}\left(s^{t}\right)
\end{gathered}
$$

and there are a similar set of conditions for the South.

There are just two assets in fixed supply, equity in the Northern intermediate goods firm, and equity in the Southern intermediate goods firm. The supply of both assets is normalized to unity. Firms are entirely equity financed. Agents do not have access to a full range of Arrow-Debreu contingent claims, and can save and share risks by holding these two assets at most. An equity contract in the Northern (Southern) intermediate goods firm entitles its owner dividend $D\left(s^{t}\right)$ $\left(D^{*}\left(s^{t}\right)\right)$ at time $t$ after the history of events $s^{t}$, paid in units of the final good of the country in which the firm is located. In the benchmark model, firms in any country are owned by three parties: domestic insiders, domestic outsiders, and foreign outsiders. ${ }^{9} \lambda_{i j\left(s^{t}\right)}($ where $i, j=N, S)$ denotes the share of country $j$ equity held by outsiders of country $i$, and $\alpha\left(s^{t}\right)$ and $\alpha^{*}\left(s^{t}\right)$ denote ownership of own-country equity by the insider in the North and the South.

\subsection{Outsiders}

There are two representative outsiders in the model, one a resident of the North and the other residing in the South. They have preferences over the final consumption good produced in their own country and leisure. The two outsiders take the wage earned at the domestic firm and the flow of dividends from the two representative intermediate goods firms as given and choose a sequence of consumption, labor supply and asset holdings. For example, the Northern outsider chooses $\left\{C\left(s^{t}\right), L\left(s^{t}\right), \lambda_{N N}\left(s^{t}\right), \lambda_{N S}\left(s^{t}\right)\right\}_{0}^{\infty}$. The maximization problem of the representative Northern agent is

\footnotetext{
${ }^{9}$ Endogenous insider ownership and asset allocation by the insider are explored in an extension of the benchmark case.
} 


$$
\max _{\left\{\mathrm{C}\left(\mathrm{s}^{\mathrm{t}}\right), \mathrm{L}\left(\mathrm{s}^{\mathrm{t}}\right), \lambda_{\mathrm{NN}}\left(\mathrm{s}^{\mathrm{t}}\right), \lambda_{\mathrm{NS}}\left(\mathrm{s}^{\mathrm{t}}\right)\right\}} \sum_{t=0}^{\infty} \sum_{s^{t}} \beta^{t} \pi\left(s^{t}\right) U\left(C\left(s^{t}\right), L\left(s^{t}\right)\right)
$$

subject to the period-wise budget constraint

$$
\begin{array}{r}
C\left(s^{t}\right)+P\left(s^{t}\right)\left(\lambda_{N N}\left(s^{t}\right)-\lambda_{N N}\left(s^{t-1}\right)\right)+e\left(s^{t}\right) P^{*}\left(s^{t}\right)\left(\lambda_{N S}\left(s^{t}\right)-\lambda_{N S}\left(s^{t-1}\right)\right) \\
=q_{a}\left(s^{t}\right) W\left(s^{t}\right) L\left(s^{t}\right)+\lambda_{N N}\left(s^{t-1}\right) D\left(s^{t}\right)+\lambda_{N S}\left(s^{t-1}\right) e\left(s^{t}\right) D^{*}\left(s^{t}\right)
\end{array}
$$

Utility in the benchmark case is given by the felicity function

$$
U(C, L)=\frac{C^{1-\gamma}}{1-\gamma}+\frac{\mu L^{1+\psi}}{1+\psi}
$$

where $\gamma$ is the coefficient of relative risk aversion, $\frac{1}{\psi}$ is the Frisch labor supply elasticity, and $\mu<0$. The special case of log utility in consumption is utilized later to derive analytical results. The first order conditions below are derived without a specific functional form for utility.

The outsider observes the history of states up to the period $t, s^{t}$, forms expectations on the future state $s_{t+1}$, and then solves for her own optimal consumption, labor supply and asset allocations. ${ }^{10}$ The first order conditions for the outsiders are standard. The Northern outsider has the following optimality conditions for stock purchases

$$
\begin{gathered}
P\left(s^{t}\right)=\beta \sum_{s_{t+1} \in \mathbb{S}} \pi\left(s_{t+1} \mid s^{t}\right) \frac{U_{C}\left(s^{t}, s_{t+1}\right)}{U_{C}\left(s^{t}\right)}\left(D\left(s^{t}, s_{t+1}\right)+P\left(s^{t}, s_{t+1}\right)\right) \\
e\left(s^{t}\right) P^{*}\left(s^{t}\right)=\beta \sum_{s_{t+1}} \pi\left(s_{t+1} \mid s^{t}\right) \frac{U_{C}\left(s^{t}, s_{t+1}\right)}{U_{C}\left(s^{t}\right)} e\left(s^{t}, s_{t+1}\right)\left(D^{*}\left(s^{t}, s_{t+1}\right)+P^{*}\left(s^{t}, s_{t+1}\right)\right)
\end{gathered}
$$

which is the standard asset-pricing Euler equation. The condition for hours worked is

$$
\begin{aligned}
U_{C}\left(s^{t}\right) q_{a}\left(s^{t}\right) W\left(s^{t}\right)+U_{L}\left(s^{t}\right) & \geq 0 \\
& =0 \text { if } L\left(s^{t}\right)>0
\end{aligned}
$$

There are a similar set of conditions for the South.

\subsection{Insiders}

This section describes the insider's optimization problem concisely. A more complete discussion of how the insider affects the equilibrium is postponed till section 4.1. The insider has sole authority

\footnotetext{
${ }^{10}$ Since expectations are rational, she can implicitly calculate expected dividend policy and current labor demand of the insider, whose problem is described in the next section.
} 
over the decisions of the representative domestic firm. I assume for the moment that the insider owns a fraction $\alpha$ of the firm's equity, but cannot perform asset trades, so that she has her entire wealth invested in domestic equity. ${ }^{11}$ The insider has the following period-wise flow of income and consumption in the North.

$$
M\left(s^{t}\right)=\alpha D\left(s^{t}\right)+q_{a}\left(s^{t}\right) f\left(s^{t}\right) Y_{a}\left(s^{t}\right)-\Phi\left(s^{t}\right)
$$

where dividends, $D\left(s^{t}\right)$ are defined by

$$
D\left(s^{t}\right)=q_{a}\left(s^{t}\right)\left[\left\{1-f\left(s^{t}\right)\right\}\left\{Y_{a}\left(s^{t}\right)\right\}-W\left(s^{t}\right) L\left(s^{t}\right)\right]-\left\{K\left(s^{t}\right)-(1-\delta) K\left(s^{t-1}\right)\right\}
$$

$f\left(s^{t}\right)$ is the fraction of revenue extracted as private benefits of control. There is an extensive literature in corporate finance documenting the extent and magnitude of private benefits of control, which in reality can take forms such as outright pilferage of firm assets, product discounts to subsidiaries, or share sales at low prices to related parties (see Barclay and Holderness, 1989; Nenova, 2003). In the paper I abstract from the precise form private benefits might take by modeling it simply as a component of the insider's consumption. Dyck and Zingales (2004) estimate private benefits of control around the world from the premium paid for blocks of controlling shares, and find a range of values. While such benefits average to around $14 \%$ of firm equity value, they may be as high as $65 \%$ of equity value in countries where institutions are weak.

$\Phi\left(s^{t}\right)$, the deadweight cost incurred by the insider to extract private benefits, can be thought of as monetary bribes, the costs of running front companies, doctoring accounts, or paying courtmandated fines in the event of litigation. The cost of stealing is assumed to take the following functional form

$$
\Phi\left(s^{t}\right)=q_{a}\left(s^{t}\right) \frac{\eta f\left(s^{t}\right)^{2} Y_{a}\left(s^{t}\right)}{2}
$$

which is quadratic in the fraction stolen and linear in the scale of stealing. ${ }^{12}$ It depends on a parameter that captures institutional quality, $\eta$. Higher values of $\eta$ correspond to better institutional quality. Thus I assume that private benefits of control are easier to extract in countries that suffer from institutional failures. This is consistent with the empirical evidence in Nenova (2003) and Dyck and Zingales (2004). Conversely, better institutions make it easier for outside investors to extract the free cash flow of a firm in the form of dividends, as in LaPorta et al. (2000b), and Dittmar et al. (2003). The value of $\eta$ may differ between the North and the South

\footnotetext{
${ }^{11}$ Endogenous insider ownership is explored in a later section.

${ }^{12}$ Fractional private benefits of control and a quadratic cost-of-stealing function are common modeling devices used in the corporate finance literature. See Shleifer and Wolfenzon (2002) and Kim and Durnev (2005) for empirical implementations, and Albuquerque and Wang (2008) for an example of a recent DSGE model that uses these functional forms to model the free cash flow problem.
} 
to reflect differences in institutional quality.

Let us consider the insider's problem in the North. She chooses $\left\{I\left(s^{t}\right), D\left(s^{t}\right), L\left(s^{t}\right), f\left(s^{t}\right)\right\}_{0}^{\infty}$, which are investments, dividends, labor demand, and fraction of output extracted as private benefits. Her maximization problem, for a given level of ownership $\alpha$, is

$$
\max _{\left\{\mathrm{I}\left(\mathrm{s}^{\mathrm{t}}\right), \mathrm{D}\left(\mathrm{s}^{\mathrm{t}}\right), \mathrm{L}\left(\mathrm{s}^{\mathrm{t}}\right), \mathrm{f}\left(\mathrm{s}^{t}\right)\right\}} \sum_{t=0}^{\infty} \sum_{s^{t}} Q\left(s^{t}\right)\left(\alpha D\left(s^{t}\right)+q_{a}\left(s^{t}\right) f\left(s^{t}\right) Y\left(s^{t}\right)-\Phi\left(s^{t}\right)\right)
$$

where $Q\left(s^{t}\right)$ is the stochastic discount factor that the insider uses to price her own flow of income after history $s^{t}$. $Q\left(s^{t}\right)$ is assumed to be

$$
Q\left(s^{t}\right) \equiv \pi\left(s^{t}\right) \beta^{t} \frac{U^{\prime}\left(M\left(s^{t}\right)\right)}{U^{\prime}\left(M\left(s^{0}\right)\right)} .
$$

The utility function of the insider is assumed to be defined only over her own consumption because she does not supply labor.

$$
U(M)=\frac{M^{1-\gamma}}{1-\gamma}
$$

The set up for the Southern insider, except for the institutional quality parameter, is identical. The Northern insider observes the history of states up to the period $t, s^{t}$, and forms expectations on the future state $s_{t+1}$. Then she decides on investment, employment and amount of private benefits based on the following conditions. The inter-temporal optimality condition for investment is given by

$$
\sum_{s_{t+1} \in \mathbb{S}} \frac{Q\left(s^{t}, s_{t+1}\right)}{Q\left(s^{t}\right)}\left[\theta\left(1+\frac{(1-\alpha)^{2}}{2 \alpha \eta}\right) \frac{q_{a}\left(s^{t}, s_{t+1}\right) Y_{a}\left(s^{t}, s_{t+1}\right)}{K\left(s^{t}\right)}+(1-\delta)\right]=1 .
$$

The static labor demand function is given by

$$
W\left(s^{t}\right) L\left(s^{t}\right)=(1-\theta)\left(1+\frac{(1-\alpha)^{2}}{2 \alpha \eta}\right) Y_{a}\left(s^{t}\right) .
$$

Optimal private benefits of control are given by

$$
f\left(s^{t}\right)=\frac{1-\alpha}{\eta} .
$$

The insider steals a constant fraction of output in each period and state, which follows directly from the quadratic cost of stealing that is assumed in much of the finance literature because it simplifies analytical results substantially. It is straightforward when solving the model numerically to generalize this to a convex cost function for appropriating private benefits of control.

Note that the presence of insider ownership introduces certain time-invariant wedges in the model as compared to a frictionless model. These wedges appear in the optimality conditions for 
capital and labor demand above. The term $\left(1+\frac{(1-\alpha)^{2}}{2 \alpha \eta}\right)$ in these two optimality conditions is the gross payoff (before deducting the insider's share of labor and investment costs) to the insider from dividends and private benefits of control (net costs of extracting that benefit) per equity share held by the insider. This payoff is lower the better is the quality of domestic institutions (higher $\eta) .{ }^{13}$ This property of the model is summarized in Proposition 1.

Proposition 1 The agency friction introduces a time-invariant wedge, $\left(1+\frac{(1-\alpha)^{2}}{2 \alpha \eta}\right)$, in the optimality condition for investment and labor. It has the following properties: (i) It decreases with better institutional quality (higher $\eta$ ); (ii) It increases labor's share of output; (iii) It increases the weight on the marginal product of capital.

Plugging in the optimal amount of private benefit to find revenues net of stealing, we get $\left(\psi_{1}-\psi_{0}\right)$ as capital's share of output, where $\psi_{1} \equiv\left(1-\frac{1-\alpha}{\eta}\right)$ is the share of gross revenues (net of private benefits) in output, and $\psi_{0} \equiv(1-\theta)\left(1+\frac{(1-\alpha)^{2}}{2 \alpha \eta}\right)$ is labor's share. Note that labor's and capital's share in GDP add up to $\psi_{1} \leq 1$ because of private benefits of control. $\psi_{1}=1$ when institutions are perfect.

\subsection{Market Clearing Conditions and Equilibrium}

Relative prices of intermediate goods, $q_{a}\left(s^{t}\right)$ and $q_{b}\left(s^{t}\right)$ adjust such that

$$
\begin{aligned}
& a\left(s^{t}\right)+a^{*}\left(s^{t}\right)=Y_{a}\left(s^{t}\right) \\
& b\left(s^{t}\right)+b^{*}\left(s^{t}\right)=Y_{b}\left(s^{t}\right)
\end{aligned}
$$

The final consumption good market clearing requires

$$
\begin{gathered}
C\left(s^{t}\right)+K\left(s^{t}\right)-(1-\delta) K\left(s^{t-1}\right)+M\left(s^{t}\right)=Y\left(s^{t}\right)-\Phi\left(s^{t}\right) \\
C_{m^{*}}\left(s^{t}\right)+K^{*}\left(s^{t}\right)-(1-\delta) K^{*}\left(s^{t-1}\right)+M^{*}\left(s^{t}\right)=Y^{*}\left(s^{t}\right)-\Phi^{*}\left(s^{t}\right)
\end{gathered}
$$

so that consumption demand by the representative outsider, investment demand and the consumption of the insider add up to the output of final goods.

Stock market clearing requires that

$$
\lambda_{N N}\left(s^{t}\right)+\lambda_{S N}\left(s^{t}\right)=1-\alpha\left(s^{t}\right)
$$

\footnotetext{
${ }^{13}$ Note here that labor's share of GDP in this model is higher than the regular case, and declines to the CobbDouglas value as $\eta$ becomes larger.
} 


$$
\lambda_{N S}\left(s^{t}\right)+\lambda_{S S}\left(s^{t}\right)=1-\alpha^{*}\left(s^{t}\right)
$$

so that the total shares held by outsiders in a country's firms is constrained by the holdings of the insider. The fractions $\left(1-\alpha\left(s^{t}\right)\right)$ and $\left(1-\alpha^{*}\left(s^{t}\right)\right)$ are the float portfolios in the North and the South.

Definition 1 An equilibrium in this model is a set of prices $P\left(s^{t}\right), P^{*}\left(s^{t}\right), R\left(s^{t}\right), R^{*}\left(s^{t}\right), W\left(s^{t}\right)$, $W^{*}\left(s^{t}\right), q_{a}\left(s^{t}\right), q_{a}^{*}\left(s^{t}\right), q_{b}\left(s^{t}\right), q_{b}^{*}\left(s^{t}\right)$, and $e\left(s^{t}\right)$ for all $s^{t}$ and $t$ satisfying the following conditions

1 The insider's investment, employment and private benefits optimality conditions (3.20), (3.21) and (3.22) hold in the North. Analogous conditions hold in the South.

2 The outsider's stock purchase and labor supply optimality conditions (3.13), (3.14) and (3.15) hold in the North. Analogous conditions hold in the South.

3 Intermediate inputs are combined optimally according to conditions (3.9) and (3.10) in the North. Analogous conditions hold in the South.

4 Intermediate inputs resource constraints (3.23) and (3.24) hold worldwide.

5 Final goods resource constraints (3.25) and (3.26) hold in each country.

6 Asset markets clear according to constraints (3.27) and (3.28).

In the equilibrium defined above, insiders make decisions regarding the investment, dividends, and labor demand of the intermediate goods firms. How their decisions influence the equilibrium is discussed in the following section (4.1). The general equilibrium effects on the international portfolio allocation of outsiders is explored in section (4.2).

\section{Analysis and Results}

\subsection{Insider Ownership and Investment Dynamics}

This section shows how insider ownership and the agency friction affect the dynamics of investment. First, it is useful to break up the insider's consumption $M\left(s^{t}\right)$ into three components,

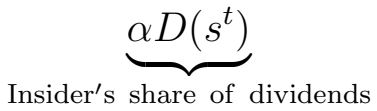

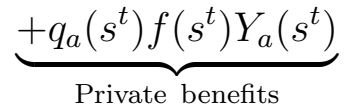

Private benefits

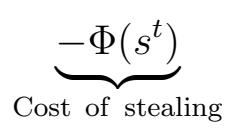


where dividends $D\left(s^{t}\right)$ are defined by

$$
\underbrace{q_{a}\left(s^{t}\right)\left(1-f\left(s^{t}\right)\right) Y_{a}\left(s^{t}\right)}_{\text {Revenue net of private benefit }} \quad \underbrace{-q_{a}\left(s^{t}\right) W\left(s^{t}\right) L\left(s^{t}\right)}_{\text {Labor costs }} \quad \underbrace{-\left\{K\left(s^{t}\right)-(1-\delta) K\left(s^{t-1}\right)\right\}}_{\text {Investment }}
$$

The agency problem in the model stems from the insider's limited ownership of the firm and her ability to extract private benefits of control. Because the insider owns only a fraction $\alpha$ of the firm, in effect $(1-\alpha)$ of her private benefits come from the revenue stream owned by outsiders. The larger the share $(1-\alpha)$ owned by outsiders, the greater the insider's incentive to steal. Thus, the optimal extraction of private benefits of control declines with greater insider ownership and increases with greater outsider ownership as in Shleifer and Wolfenzon (2002) and Albuquerque and Wang $(2006,2008)$, as shown by the insider's optimality condition (3.22)

$$
f\left(s^{t}\right)=\frac{1-\alpha}{\eta}
$$

Multiplying the expression for dividends by the insider's ownership share $\alpha$ and inspecting the last two terms, we see that the insider pays for only a fraction $\alpha$ of the labor and investment cost of the firm due to her limited ownership.

$$
\underbrace{-\alpha\left\{q_{a}\left(s^{t}\right) W\left(s^{t}\right) L\left(s^{t}\right)\right\}}_{\text {Insider's share of labor costs }}
$$

$$
\underbrace{-\alpha\left\{K\left(s^{t}\right)-(1-\delta) K\left(s^{t-1}\right)\right\}}_{\text {Insider's share of investment costs }}
$$

Since private benefits are proportional to firm size by assumption and the higher costs of a larger firm are partly subsidized by outside owners, the insider has an incentive to over-invest and overemploy. This distinguishes the agency aspect of the model from Albuquerque and Wang (2008), who focus only on over-investment. Ceteris paribus, the imperfect substitutability of capital and labor leads to higher equilibrium capital stock as well as greater demand for labor compared to an environment without corporate governance frictions. ${ }^{14}$

For symmetric countries, the steady state capital-output ratio and investment-output ratio are respectively $\frac{\theta \phi}{\frac{1}{\beta}+\delta-1}$ and $\frac{\delta \theta \phi}{\frac{1}{\beta}+\delta-1}$, where $\phi \equiv\left(1+\frac{(1-\alpha)^{2}}{2 \alpha \eta}\right)$, the corporate governance driven wedge introduced in Proposition 1, is higher when institutions are weaker. We cannot solve for equilibrium non-steady-state investment rates in closed form in a discrete time framework. ${ }^{15}$ However, expanding the investment optimality condition using the definition of covariance gives us some intuition.

\footnotetext{
${ }^{14}$ This implication of the model may seem counter-intuitive at face value. But note that the claim here is that the South will have higher per capita capital stock only when its productivity is the same as the North. Albuquerque and Wang (2008) provide cross country evidence of higher investment rates in countries with lower corporate governance standards. Also, there is a wealth of anecdotal evidence of over-investment by poorly governed firms in Asia leading up to the 1997-1998 crisis.

${ }^{15}$ Albuquerque and Wang (2008) derive a closed form expression for the investment rate in a continuous time framework and show that investment rates increase with weaker investor protection.
} 


$$
\mathbb{E}_{t}\left(\frac{Q_{t+1}}{Q_{t}}\right)\left[\theta \phi \mathbb{E}_{t}\left(\frac{q_{a t+1} Y_{a t}}{K_{t}}\right)+(1-\delta)\right]=1-\theta \phi \operatorname{Cov}_{t}\left(\frac{q_{a t+1} Y_{a t}}{K_{t}}, \frac{Q_{t+1}}{Q_{t}}\right)
$$

The covariance term on the right hand side of the expression is negative since the insider is nondiversified. This, ceteris paribus, leads to lower capital stock, that is, makes the insider reluctant to over-invest when $\eta$ is lower. Since the insider is risk averse and her consumption stream is derived entirely from the firm, over-investment reduces her utility by increasing the volatility of her consumption stream. However, the first order effect is the incentive to over-invest which can be seen in the term for the expected returns to investment $\theta \phi \mathbb{E}_{t}\left(\frac{q_{a t+1} Y_{a t}}{K_{t}}\right)$. Weaker institutions increase this incentive.

\subsection{Analytical Solutions for Outsider Portfolios}

The previous section outlined the intuition for insider over-investment in countries with weaker institutions. In this section I demonstrate that the general equilibrium effects of the insider's decision on outsider portfolios is to make them biased towards domestic assets. In order to do so, I follow Heathcote and Perri $(2004,2009)$ in making a number of simplifying assumptions to solve for outsider portfolios analytically.

Assumption 1 North and South are ex-ante symmetric. Specifically, $\eta=\eta^{*}$ and $\alpha=\alpha^{*}$.

Assumption 2 The utility of outsiders is logarithmic in consumption $(\gamma=1)$.

Assumption 3 The final goods technology that combines Northern and Southern intermediates is Cobb-Douglas $(\sigma=1)$.

Under these conditions, a constant portfolio rule that replicates the complete markets outcome for outsiders exists. ${ }^{16}$ Proposition 2 below provides intuition for the results of the numerical simulations that follow and highlights the main qualitative mechanisms at work. The more interesting and relevant case of two countries with different institutional quality is explored numerically. ${ }^{17}$ The solution in Proposition 2 can be thought of as equity positions that decentralize a central planner's problem that maximizes the equally weighted sum of outsider utilities, given optimal behavior by the insiders in each country. ${ }^{18}$ I prove the proposition by showing that under the allocations implied by this portfolio rule, all equilibrium conditions are satisfied.

\footnotetext{
${ }^{16}$ Since $\gamma=1$ and $\sigma=1$, the condition $\gamma \sigma=1$ needed for the replicability of the complete markets outcome with only equities discussed in Obstfeld and Rogoff (2000) page 364 holds.

${ }^{17}$ This problem, due to the ex-ante asymmetry of the countries in question, cannot be solved by the simple algebra used in this section.

${ }^{18}$ Note that the solution for $\lambda$ below represents the fraction of the domestic firm owned by the domestic agent, as well as the fraction of domestic wealth invested in domestic assets. This is true because of the ex-ante symmetry of the countries assumed in this section, and will not be true in general.
} 
Proposition 2 There exists an equilibrium for this economy with own-country portfolio share for outsiders, $\lambda_{N N}=\lambda_{S S}=\lambda$, such that the consumptions of outside investors are equated across symmetric countries in all states of nature. The value of $\lambda$ is given by

$$
\lambda=(1-\alpha)\left[\frac{1}{2}+\frac{1}{2}\left\{\frac{\psi_{0}(2 \omega-1)}{1-\left(1-\psi_{0}\right)(2 \omega-1)}\right\}\right]
$$

where

$$
\psi_{0}=(1-\theta) \phi
$$

is labor's share of total income, and $\phi \equiv\left(1+\frac{(1-\alpha)^{2}}{2 \alpha \eta}\right)$, is the gross payoff per share to the insider. The degree of home bias, given by $\frac{1}{2}\left\{\frac{\psi_{0}(2 \omega-1)}{1-\left(1-\psi_{0}\right)(2 \omega-1)}\right\}$, is decreasing in institutional quality.

Proof: See appendices (A.1).

Proposition 2 gives us insights and testable predictions about two determinants of international diversification that have so far remained unexplored in an international business cycle framework. The first piece in the solution, $\frac{1-\alpha}{2}$, is the minimum-variance portfolio used for pure diversification. Since only a fraction $(1-\alpha)$ of the world market portfolio is part of the float, each representative outsider holds $\frac{1-\alpha}{2}$ by symmetry. The first insight from Proposition 2 is that the float portfolio should play a major role in determining a country's diversification potential. The smaller the float portfolio, the less internationally diversified a country will be.

The second piece, $\frac{1}{2}\left\{\frac{\psi_{0}(2 \omega-1)(1-\alpha)}{1-\left(1-\psi_{0}\right)(2 \omega-1)}\right\}$, hedges against labor-income risk. The size of this portion of the portfolio increases when institutional quality is lower. The literature, since the seminal work of Cole and Obstfeld (1991), has only focused on trade openness as a determinant of the hedge portfolio. What Proposition 2 highlights is that two other factors, the float portfolio and institutional quality, are also at play. The empirical importance of these two factors is explored later in section 5.

\subsubsection{Intuition Using Covariances of Endogenous Variables}

Proposition 2 highlighted the effect of two factors in determining country portfolios: the supply of assets given by the float portfolio, and institutional quality. To get further insight about the macroeconomic channels through which Proposition 2 works, the portfolio in Proposition 2 is expressed as a covariance ratio of a few key endogenous variables. It will be argued later that these covariances are influenced in general equilibrium by institutional quality and investor protection.

Lemma 1 The portfolio $\lambda$ can be expressed as

$$
\lambda \approx(1-\alpha)\left[\frac{1}{2}-\frac{1}{2} \Psi \frac{\operatorname{cov}(\Delta \hat{\mathbb{L}}, \Delta \hat{D})}{\operatorname{var}(\Delta \hat{D})}\right]
$$


where

$$
\Psi=\frac{\overline{\mathbb{L}}}{\bar{D}(1-\alpha)}=\frac{\theta \psi_{0}{ }^{2} \omega^{\omega} 1-\omega^{1-\omega}}{\left[(1-\theta)\left(\psi_{1}-\psi_{0}\right)\left(\frac{1}{\beta}+\delta-1\right)-\delta\right](1-\alpha)}
$$

and $\mathbb{L}=q_{a} W L=$ Labor income, $\mathrm{D}=$ Dividends, $\Delta \hat{\mathbb{L}}=\hat{\mathbb{L}}-\hat{e}-\hat{\mathbb{L}}^{*}, \Delta \hat{D}=\hat{D}-\hat{e}-\hat{D}^{*} .{ }^{19}$

Proof: See appendices (A.1).

The expression in Lemma 1 is intuitive. ${ }^{20}$ First, since only the float portfolio $(1-\alpha)$ can be held by outside investors, $(1-\alpha)$ represents the total supply of freely traded assets in the world and appears in both the diversification and hedging parts of the portfolio. Second, the size of the labor-income-risk hedging part is determined by the product of two quantities. The first is the relative importance of labor income compared to dividend income for outside investors in the steady state, given by the ratio $\Psi=\frac{\overline{\mathbb{L}}}{\bar{D}(1-\alpha)}$. As noted before in Observations 1 and 2, weaker institutions make this ratio higher both through a higher labor share of GDP caused by inefficient firm sizes, and through a lower dividend share of GDP caused by private benefit extraction and steady state over-investment. Higher $\frac{\overline{\mathbb{L}}}{\bar{D}(1-\alpha)}$, on average, increases the need to hedge labor income risk, thereby making any asset that does so more attractive to outsiders. This asset turns out to be domestic portfolio because of the second component in the hedge portfolio, $\frac{\operatorname{cov}(\Delta \hat{\mathbb{L}}, \Delta \hat{D})}{\operatorname{var}(\Delta \hat{D})}$.

To get insight into the determinants of the ratio $\frac{\operatorname{cov}(\Delta \hat{\mathbb{L}}, \Delta \hat{D})}{\operatorname{var}(\Delta \hat{D})}$, it is straightforward to express it in terms of the deep parameters of the model by comparing the expressions in Proposition 2 and Lemma 1. This gives us Lemma 2.

Lemma 2 The covariance-variance ratio $R \equiv \frac{\operatorname{cov}(\Delta \hat{\mathbb{L}}, \Delta \hat{D})}{\operatorname{var}(\Delta \hat{D})}$ can be expressed as the following function of underlying parameters:

$$
R \approx-\frac{(1-\alpha)(2 \omega-1)\left\{(1-\theta)\left(\psi_{1}-\psi_{0}\right)\left(\frac{1}{\beta}+\delta-1\right)-\delta\right\}}{\theta \psi_{0} \omega^{\omega} 1-\omega^{1-\omega}\left\{1-\left(1-\psi_{0}\right)(2 \omega-1)\right\}}
$$

Proof: Follows from comparing the expressions in Proposition 2 and Lemma 1.

Note that $\frac{\operatorname{cov}(\Delta \hat{\mathbb{L}}, \Delta \hat{D})}{\operatorname{var}(\Delta \hat{D})}$ is negative whenever $\omega>\frac{1}{2}$, so that countries have a preference for the domestic intermediate good in their final consumption bundle. To see why, consider a positive productivity shock in one country. The increase in domestic investment due to the technology shock reduces dividends here relative to the other country. The shock also directly leads to an increase in labor income through an increase in output, although it worsens the terms of trade,

\footnotetext{
${ }^{19}$ Hats over variables denote log deviations from symmetric steady state values and bars above variables denote symmetric steady state values.

${ }^{20}$ As emphasized by Heathcote and Perri (2009), the portfolio can be expressed in terms of the covariance between different components of income across the two countries because of the no-trade result implicit in Proposition 2. With no trade in assets in equilibrium, asset income derives only from dividends and not from realized capital gains or losses. Thus asset income rather than asset returns determines portfolios.
} 
dampening the rise in labor income relative to the other country. This is the "automatic insurance" role of the terms of trade emphasized by Cole and Obstfeld (1991) in the context of an endowment economy where changes in endowment are offset exactly by changes in the real exchange rate to keep the value of income (and consumptions) of the two countries the same. However, the increase in domestic investment due to the positive shock to technology increases demand for the domestic intermediate good relative to the foreign intermediate good as long as $\omega>\frac{1}{2}$, mitigating the decline in the terms of trade. This leads to an overall increase in labor income in the country experiencing the positive technology shock, relative to the other country, because the direct positive effect of a productivity increase is not offset by the worsening of the terms of trade. Note that this effect is driven by the dynamics of investment and the home-bias in composition of investment goods, so that when $\omega=\frac{1}{2}$, the effect disappears and $\frac{\operatorname{cov}(\Delta \hat{\mathbb{L}}, \Delta \hat{D})}{\operatorname{var}(\Delta \hat{D})}=0$.

The same forces are at work in this model. However, the presence of the insider amplifies the connection between investment and the two income streams of outside investors. The key mechanism at work is the sharper response of investment following shocks due to 'empire-building' by insiders, and the effect this has on terms of trade movements following shocks. Recall that, ceteris paribus, higher investment improved the terms of trade by increasing the demand for the domestic intermediate good following a good shock. What effect does this have on outsider incomes? Consider labor income first. The worsening of the terms of trade after a good shock tended to have a cross-border insurance effect by lowering the divergence between the value of domestic and foreign labor income. Following the shock, insiders also find it optimal to reduce dividends below first-best to finance privately optimal projects in expectation of higher future private benefits of control. This leads domestic dividends to decline by more than in a frictionless model, increasing the negative correlation between labor and asset income generic to these class of models. This insight is summarized in the following proposition.

Proposition 3 Country portfolios have a larger share of foreign assets when institutional quality is better since: (i) International diversification is increasing in the ratio $R \equiv \frac{\operatorname{cov}(\Delta \hat{\mathbb{L}}, \Delta \hat{D})}{\operatorname{var}(\Delta \hat{D})}$, or $\frac{\partial \lambda}{\partial R}>0$ and (ii) the ratio $R$ is increasing in institutional quality, or $\frac{\partial R}{\partial \eta}>0$.

Proof: Follows directly from Lemmas 1 and 2 by taking the derivative of $\lambda$ with respect to $R$, and of $R$ with respect $\eta$.

Section 5 tests these predictions about diversification and the ratio $R$ empirically, finding evidence consistent with $R$ being the 'missing link' between capital flows and institutions.

Propositions 2 and 3 assume institutionally symmetric countries and thus work through the magnification of the terms of trade effects generic to this class of models, and the higher labor shares in both countries. They are useful mainly because analytical solutions are able to identify the channels through which home bias works in this model. They are also instructive when thinking about the cross holdings we might expect in a world where all countries have similar, but variable 
institutional quality; or when conducting the comparative static exercise of raising (or lowering) institutional quality simultaneously in two countries that have bilateral equity positions. They cannot shed light on the magnitude of the institutional quality channel when $\eta \neq \eta^{*}$. But the model has a channel by which relative labor and asset income are negatively correlated, independent of terms of trade effects when countries are asymmetric: Following a positive technology shock in the South, relative labor and income goes up, and relative dividend income goes down driven by relative over-investment in the South. In the special case where we are able to solve for portfolios analytically, this channel is eliminated completely because $\eta=\eta^{*}$ and these relative quantities move identically. All theories of home-biased portfolios assume some form of country asymmetry. For example, the terms of trade effects described in Heathcote and Perri (2009) and utilized in this

section are driven by home bias in final goods $\left(\omega>\frac{1}{2}\right)$. Thus exploring country heterogeneity in institutional quality is interesting because we can expect to find large quantitative effects driven by institutional asymmetry. Thus, section 4.4 presents results from solving the model numerically for the case when $\eta \neq \eta^{*}$.

\subsection{Relation to Existing Literature}

The papers that are closest to mine are Albuquerque and Wang (2006, 2008), referred to as AW (2006) and AW (2008). AW (2006) study the investment and exchange rate effects of investor protection. They solve for equilibrium consumption allocations of outsiders under the assumption of asset market completeness and find portfolios that support these allocations. In their equilibrium, outsiders in each country hold claims on each other that are independent of the degree of investor protection because of the presence of a full set of contingent assets. In the present paper, the focus is on portfolio allocation when the available assets are just equity in Northern and Southern firms. On the production side, the present model uses labor inputs, and this brings inefficient employment as an additional source of misalignment of incentives between insiders and outsiders. The inclusion of labor turns out to have implications for hedging labor income risk, and makes outsider portfolios dependent on institutional parameters. My results on the volatility of investment in countries with lower investor protection is echoed by AW (2008), which is a closed economy variant of AW (2006). One of its contributions is to derive a closed form solution for investment rates in a continuous-time framework. Their theory predicts investment rates decreasing in investor protection, a prediction that is borne out in their empirical investigation. Thus the focus of both AW (2006) and AW (2008) is on the cross-section of macroeconomic aggregates like investment, stock market volatility, exchange rates and stock prices, while I attempt to quantify the connection between institutional quality and international capital flows.

My results on home bias are closely related to those in Heathcote and Perri (2009) and Coeurdacier and Gourinchas (2012) referred to as HP (2009) and CG (2012). Specifically, the solution in Proposition 2 approaches the portfolio in HP (2009) when three conditions are satisfied: (i) 
institutional quality in both countries is perfect; (ii) insider ownership in both countries is very close to zero; (iii) there is perfect alignment of interests between the insider and the outsider, in the sense that the insider uses a weighted average of discount factors of the firm's owners to value the stream of dividends. Under these conditions, the portfolio described above converges to $\lambda=\frac{\omega+\theta-2 \omega \theta}{1+\theta-2 \omega \theta}$, the portfolio in HP (2009). CG (2012) generalize the insights in HP (2009) in a model with bonds and equity. They show that real exchange rate risk can be effectively hedged by holding bonds since real exchange rates are highly correlated with relative bond returns. Conditional on bond returns, equity home bias can arise as an effective hedge against other sources of non-diversifiable risk such as shocks to labor income. CG (2012) also provide robust evidence that country bond and equity portfolios correspond closely to values suggested by empirical estimates of the key covariance ratio $\frac{\operatorname{cov}(\Delta \hat{\mathbb{L}}, \Delta \hat{D})}{\operatorname{var}(\Delta \hat{D})}$. Thus CG (2012) provide crucial empirical validation for the connection between equity home bias and labor income risk. The present paper builds on the insights of HP (2009) and CG (2012) by introducing differences in institutional quality as an additional determinant of portfolio positions.

\subsection{Portfolios with Heterogeneous Institutions}

This section lays out the results from solving the benchmark model from section 3 numerically. The time-invariant portfolio derived in the previous sections rested on country symmetry, and needs to be solved for numerically when countries differ in institutional quality.

\subsubsection{Numerical Solution: Method and Calibration}

In order to solve the model, I implement numerically a variant of the fixed-point procedure used in Devereux and Sutherland (2011) and Tille and Van Wincoop (2010). I describe this procedure in detail in the appendices. In short, I find Taylor-series approximations of the optimal decision rules for the control variables and the transition equations of the endogenous state variables using the algorithms provided in Schmitt-Grohé and Uribe (2004), choosing the non-stochastic steadystate of the model as the approximation point for non-portfolio variables. As is well-known, steady state or zero-order portfolio shares cannot be solved for using the same non-stochastic or zero-order steady-state equations that are utilized for finding the steady state for non-portfolio variables. Instead, second-order approximations of the portfolio Euler equations along with firstorder approximations of other model equations are necessary to capture the effect of uncertainty. The steady state of the portfolio variables are found by making a guess for these and then using an iterative procedure to verify that a key optimality condition holds up to a second order of approximation. ${ }^{21}$ This condition is evaluated in practice by using only the first-order component of the decision rules for non-portfolio variables, because these depend only on the zero-order

\footnotetext{
${ }^{21}$ In particular, I verify if $E_{t}\left[\gamma\left(\hat{R}_{x, t+1}-\hat{e}_{t+1}\right)\left(\hat{C}_{t+1}^{*}-\hat{C}_{t+1}\right)+\hat{e}_{t+1} \hat{R}_{x, t+1}-\hat{e}_{t+1}^{2}\right]<\epsilon$ for some suitably small $\epsilon$.
} 
portfolio. The procedure is validated by confirming that in the special case where Proposition 2 holds, it converges to the known analytical solution from any arbitrary initial guess, with minimal error in the optimality condition (of the order of $10^{-18}$ ). I also apply this procedure to a number of other cases when closed-form and exact analytical solution for portfolios do not exist $(\sigma \neq 1$ or $\gamma \neq 1$ ). A graph of the errors in the optimality condition derived from the model's asset Euler equations in one such case is provided in the appendix, showing that there exists a unique portfolio share at which the expression is minimized. Sample Matlab ${ }^{\circledR}$ files used to implement this procedure are available on the author's webpage.

The time period of the model is a quarter. Parameter values for the benchmark model are taken from Heathcote and Perri (2009). The discount rate is $\beta=0.99$, capital's share of output is $\theta=.34$, and depreciation is $\delta=.025$. The import share is set at 0.15 and the weight $\omega$ of home intermediate goods in the aggregating function is calibrated accordingly. The benchmark case assumes that the elasticity of substitution between home and foreign intermediate good, $\sigma$, and the coefficient of relative risk aversion for the outsider, $\gamma$, are both $1 .^{22}$ The weight on labor in the additive disutility function, $\mu$, is adjusted so that the fraction of time spent working is 0.3 . The exponent of labor in this function, $\psi$, is set to 1 . The insider is assumed to have logarithmic utility in consumption only. The shock process has an autocorrelation coefficient of 0.91 , and the standard deviation of the technology shock is 0.006 . There are no contemporaneous or lagged spillover effects.

The effect of institutional quality on outsider portfolios is quantified using data from Dyck and Zingales (2004) to calibrate the institutional quality parameters $\eta$ and $\eta^{*}{ }^{23}$ Institutional quality in the North is assumed to be perfect $(\eta=\infty)$, while the institutional quality parameter in the South $\left(\eta^{*}\right)$ is varied to match the different deciles of private benefits of control reported in Dyck and Zingales (2004). Higher private benefits correspond to lower institutional quality, so that the first decile of private benefits corresponds to the best quality institutions possible in the South, the second decile of benefits correspond to second highest institutional quality, and so on. ${ }^{24}$ Insider ownerships in the North and the South in the benchmark calibration are set to $20 \%$ and $78 \%$,

\footnotetext{
${ }^{22}$ I verify that one can solve for the zero-order portfolio using alternative values of $\sigma$ and $\gamma$ (see the appendix for an example). Heathcote and Perri (2009), in a similar model, simulate portfolios under varying final goods production technology and utility functions using different values of the elasticity of substitution $\sigma$ between intermediate goods, and the coefficient of relative risk aversion $\gamma$. They find that for the range of values for these parameters used in the macro literature, the mechanism underlying Propositions 2 and 3 remains intact.

${ }^{23}$ Dyck and Zingales (2004) follow Barclay and Holderness (1989) in using the premium paid per share for controlling blocks compared to shares trading on the market to infer private benefits of control. Since the premium paid is likely to be proportional to private benefits net of the cost paid to extract such benefits, the calibration of $\eta$ targets the present discounted value of steady state net private benefits as a fraction of the steady state stock price. This equals $\frac{\left(f-\frac{\eta f^{2}}{2}\right) q_{a} Y_{a}}{\alpha D}=\frac{\left(1-\alpha^{2}\right)}{2 \alpha \eta}\left[\left(\bar{\psi}_{1}-\bar{\psi}_{0}\right)-\delta \frac{\theta}{1-\theta} \frac{\bar{\psi}_{0}}{\frac{1}{\beta}+\delta-1}\right]^{-1}$, which is the premium paid per unit of stock owned.

${ }^{24}$ Dyck and Zingales (2004) find that controlling blocks sell at a discount of $-0.01 \%$ in one country in their sample. I assume for simplicity that the country with the best institutional quality has zero private benefits, which happens to be the first decile of private benefits in the data.
} 
which are the figures for the United States and Uruguay respectively, the latter chosen because it has the highest ownership concentration in the Dyck and Zingales (2004) data. ${ }^{25}$ At each step, the equilibrium share of each asset in the wealth of each country's outsider is computed by the procedure described above. ${ }^{26}$

\subsubsection{Results}

Since stock prices and the degree of insider ownership in the two countries differ, it is not informative to look simply at the share of wealth devoted to each asset without comparing it to some benchmark. The correct benchmark in this case is a portfolio in which a constant fraction of wealth, equal to the weight $m_{i}$ of an asset in the world float portfolio, is allocated to each of the two available assets. ${ }^{27}$ The bias for country $i=N, S$ is measured as the share of wealth held in domestic assets divided by the CAPM weight $m_{i}$,

$$
H B_{i}=\frac{\frac{\lambda i i \times P_{i}}{\lambda i i \times P_{i}+\lambda i j \times P_{j}}}{m_{i}} \quad i, j=N, S
$$

where $P_{i}$ and $\lambda$ denote the stock price and equity shares, and $m_{i}=\frac{\left(1-\alpha_{i}\right) \times P_{i}}{\left(1-\alpha_{i}\right) \times P_{i}+\left(1-\alpha_{j}\right) \times P_{j}}$.

The results from the numerical solution are shown in Figure 3 below. This plots $H B_{i}$ for the North and South outsiders against the deciles of Southern private benefits (moving to the right on the horizontal axis thus corresponds to lower institutional quality). The computed home bias measure increases for both countries as institutional quality declines in the South, which confirms the analytical results for symmetric countries. Also note that the difference between the measure for the South and the North increases as institutional quality declines. The effect is largest for the last two deciles of institutional quality, which correspond to net private benefits of approximately $49 \%$ and $35 \%$ of firm value in the Dyck and Zingales (2004) data. Simulations with higher counterfactual levels of private benefits, which are not reported, show that the model can generate higher levels of bias for domestic assets. For comparison, I also plot the same home bias measure for the symmetric case assuming insider ownership to be fixed at the average value of

\footnotetext{
${ }^{25}$ The lowest value for insider ownership in their data is for the United Kingdom (18\%).

${ }^{26}$ Two points should be noted here. The first is that, in the model, countries with lower institutional quality, ceteris paribus, have higher capital stock and GDP resulting from empire-building. This counterfactual feature of the model does not seem as unrealistic once one recalls that the countries have been assumed to have the same steady state productivity. It would be straightforward to posit realistic differences in steady state productivity to remove this anomaly. I choose not to do so since the focus of the analysis is on the share of wealth held by outsiders in foreign equity. Note also that in the symmetric version of the model, the share of wealth held in any asset was simply twice the fraction of the firm owned by an outsider, by symmetry. However, in the asymmetric model such a simple relationship does not hold because the total value of the stock market differs across the two countries, even ex-ante.

${ }^{27}$ For example, when the North has perfect institutions and the South lies at the first decile of institutional quality (last decile of private benefits) stock prices are 3.6658 and 2.4795 respectively. Since the size of the float portfolio in the North and South are 0.80 and 0.22 respectively, world stock market capitalization stands at $0.8 \times 3.6658+0.22 \times 2.4795=3.4781$. Thus the benchmark weights for North and South equity in any asset portfolio are $m_{N}=\frac{2.9364}{3.4781}=0.84$ and $m_{S}=\frac{0.5455}{3.4781}=0.16$ respectively.
} 


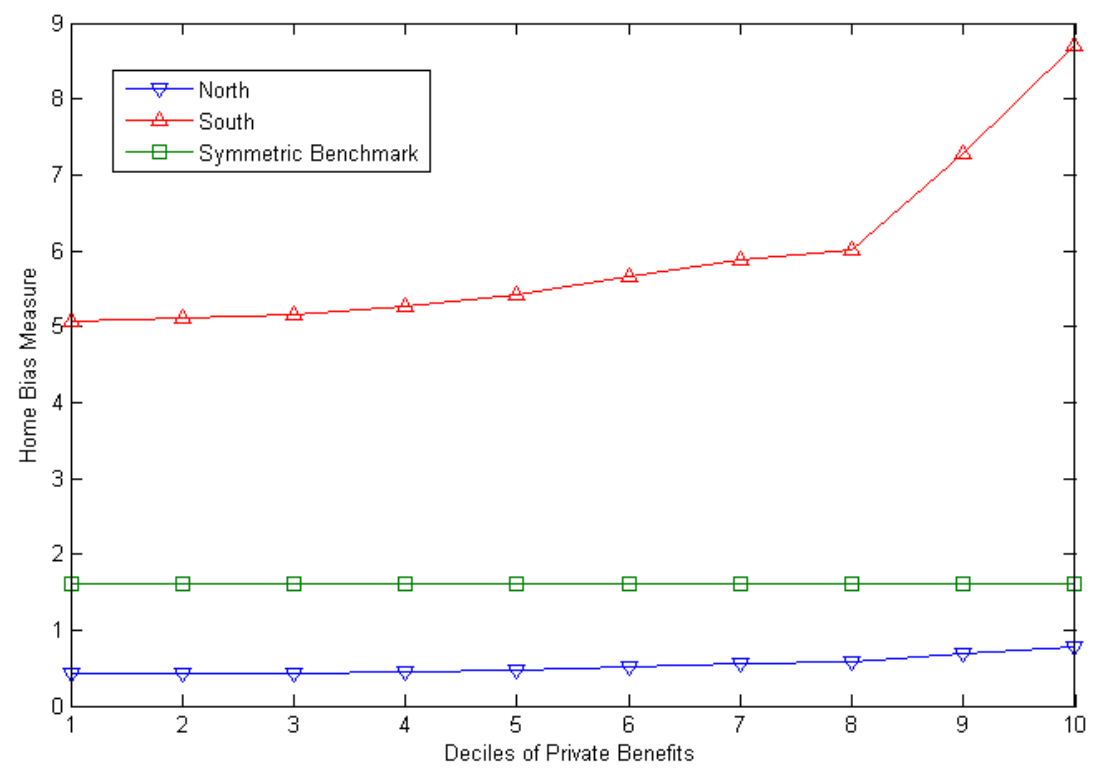

Figure 3: HOME BIASED PORTFOLIOS WITH HETEROGENEOUS INSTITUTIONS. Notes:Institutional quality, measured by the deciles of private benefits, on the x-axis (lower numbers correspond to better institutions); a measure of home bias in asset portfolios on $\mathrm{y}$-axis (details in the text).
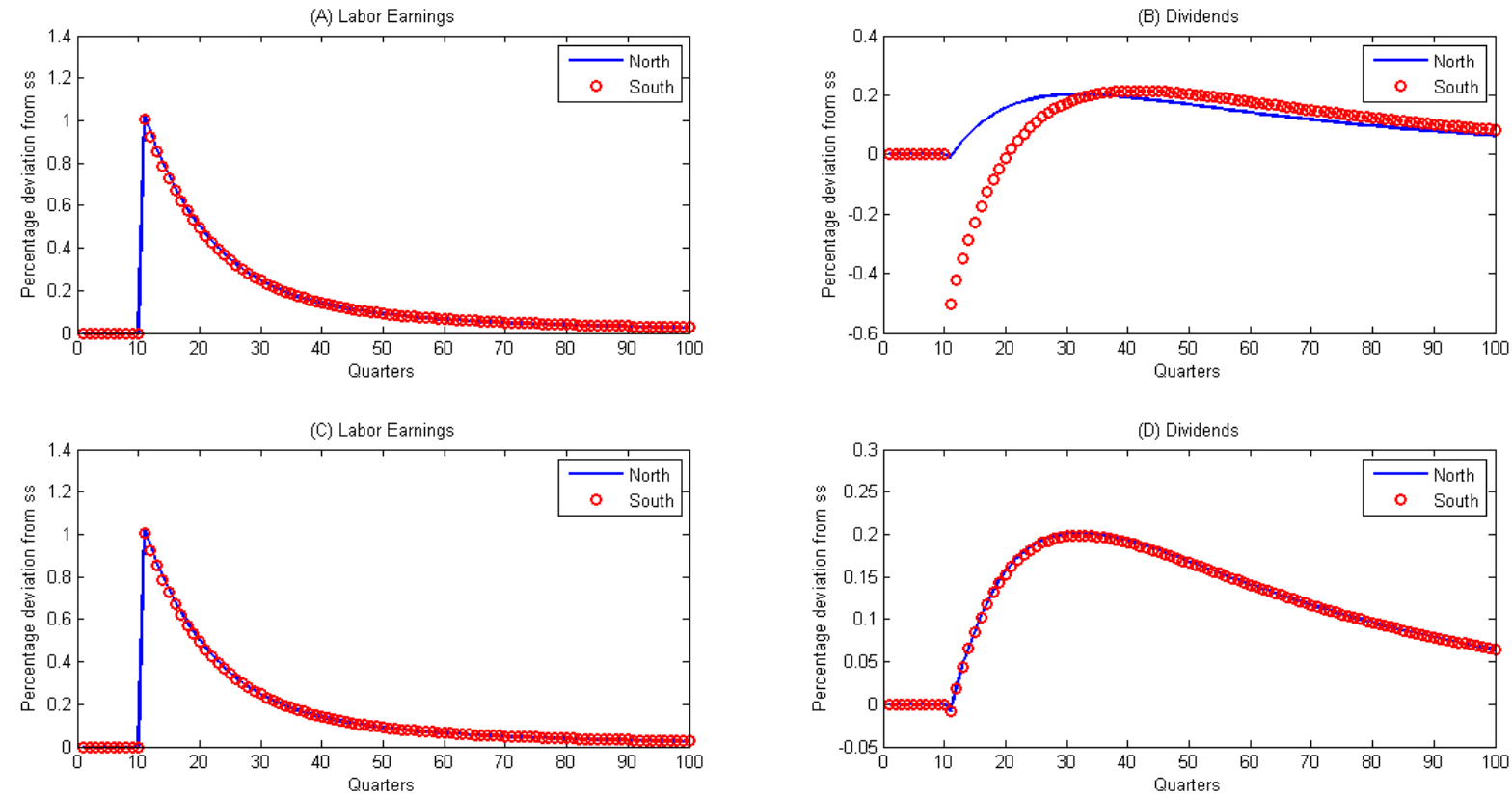

Figure 4: IMPULSE RESPONSE FUNCTIONS WITH HETEROGENEOUS INSTITUTIONS.

Notes:Time path of dividend income and labor income in two alternative scenarios. Panels

(A) and (B) - high and low institutional quality in North and South respectively. Panels

(C) and (D) - both countries have high institutional quality. 
0.49 in both countries. The South is more home biased than the symmetric case while the North is less so. ${ }^{28}$ The precise numbers should be interpreted with caution since they come out of a two-country model, while the real world is populated by a continuum of countries with differing institutional quality and insider ownership. Such a model would be extremely computationally intensive to solve and is left for future research. However, these simulations show that even this simple two-country model is able to generate the stylized patterns of capital flows that we observe in the data - that there is significant cross-sectional correlation between institutional quality and the preference for domestic over foreign assets. This correlation cannot be explained by currently existing models of international capital flows.

As discussed earlier, the macroeconomic mechanism underlying this effect originates in the dynamics of dividends and labor income following technology shocks. The impulse response functions in Figure 4 plot the time path of these variables after a simultaneous 1 percent increase in productivity in both countries. Panels (A) and (B) depict the situation when the North has perfect institutions and the South has institutional quality in the lowest decile, while panels (C) and (D) corresponds to both countries having perfect institutional quality. In panel (B), dividends decline on impact in the South while in panel (D) they increase. In both panels (A) and (B) labor income goes up on impact. Thus dividend and labor income move in opposite directions in the South in the period of the shock, driving the Southern preference for domestic assets. The following section tests this mechanism using data on international macroeconomic aggregates.

\section{Empirical Evidence}

The model's predictions can be taken to the data in a number of ways. First, the model predicts that investment volatility should be higher in the South. Second, Proposition 2 predicts that the degree of insider ownership, or conversely, the size of the float portfolio, and institutional quality, should be significant determinants of international diversification. Third, Proposition 3 suggests that country equity portfolios should depend on the second moments of relative labor income and relative dividend income, and the latter in turn should depend on institutional quality through general equilibrium effects. In all the results that follow, I use the investor protection indices from LaPorta et al. (1998) as the measure of institutional quality, but the results remain unchanged with the Kaufmann et al. (2008) indices.

The first of these effects can be seen graphically in Figure 5 below, which plots investment volatility, measured as the standard deviation of fixed capital formation growth, versus institutional quality. The data on fixed capital formation come from WorldBank (2008).

\footnotetext{
${ }^{28}$ Outsiders start with a significant degree of home bias in their portfolios even when both countries have good institutions, which, as shown by Heathcote and Perri (2009) and (Coeurdacier et al., 2010; Coeurdacier and Gourinchas, 2012) is a generic feature of these class of models.
} 


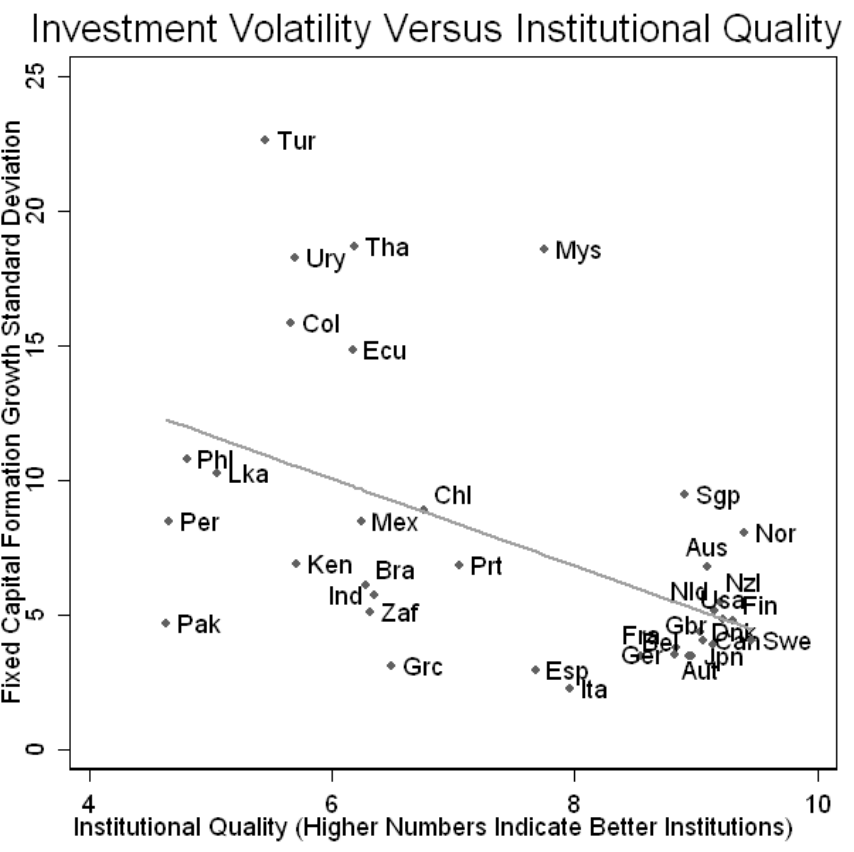

Figure 5: INVESTMENT VOLATILITY AND INSTITUTIONS.

Notes:Standard deviation of fixed capital formation growth rate over 1996-2004 for each country measured on y-axis. Institutional quality measured by the LaPorta et al. (1998) indices on the x-axis. Data source: WorldBank (2008) and LaPorta et al. (1998).

\subsection{Testing Proposition 2}

Proposition 2 highlights insider ownership and institutions as major determinants of international diversification after controlling for other factors like trade openness. OLS regressions reported in the appendix (A.2) are used to test this prediction. Institutions, measured both by the LaPorta et al. (1998) and Kaufmann et al. (2008) indices, turn out to be significant after controlling for factors that have been shown in the empirical literature (see Dahlquist et al., 2003; Kho et al., 2009; Faria et al., 2007; Coeurdacier, 2008) to be important determinants of international diversification such as country size (GDP), the level of general development (per capita GDP), openness to trade (share of total trade in GDP), the level of financial development (domestic credit to GDP ratio), financial openness (the (Chinn and Ito, 2008) index), and insider ownership (fraction of market capitalization closely held). ${ }^{29}$ Importantly, insider ownership, institutional quality and trade openness are the only variables that are significant in the regression with all controls included. This is exactly in line with Proposition 2.

\footnotetext{
${ }^{29}$ Only the regression for the sum of equity assets and liabilities using the LaPorta et al. (1998) indices are reported for brevity. When run separately, the results are stronger for foreign liabilities than assets, which is intuitive. My results for liabilities are in line with the findings Faria et al. (2007) and Faria and Mauro (2009).
} 


\subsection{Testing Proposition 3}

The last prediction, that the covariance between relative labor income and relative dividend income, divided by the variance of the latter should be higher in countries with higher institutional quality and lead to more international diversification, comes from Proposition 3. To test this prediction I construct broad measures of dividend and labor income for each country in the sample following the procedure in Heathcote and Perri (2009). This simplification is made to retain a large sample of countries that have sufficient variation in the institutional quality measure. Papers such as Coeurdacier and Gourinchas (2012), using more accurate measures of labor and capital income, find results similar to mine for a smaller set of relatively homogenous countries. All the data used in this section is from WorldBank (2008).

I use capital's share of GDP minus domestic fixed capital formation to proxy dividends, and labor's share of GDP to proxy labor income. The share of labor in GDP is the same as the calibration in the model. The quantity series from the World Development Indicators are PPP adjusted in current prices and expressed in current US Dollars. Hence, they correspond precisely with the real quantities defined I start with the same sample of 43 countries for which stylized facts were presented in section 2. I am left with 38 countries and the years 1970-2007 due to fixed capital formation data unavailability. ${ }^{30}$ I conduct the analysis on the data in logarithms. For the logarithmic series, the analysis is possible only for a subset of 32 countries for which dividend income, as calculated, do not take negative values. Taking each country $i$ as the baseline, I construct dividend income and labor income for the "rest of the world" by weighting each country $j \neq i$ in the sample with its share of "world" GDP, where "world" denotes all $j \neq i$. Next I construct the nominal exchange rate between a country and the rest of the world by the same procedure, both GDP weighting and trade weighting the bilateral exchange rates to arrive at a measure of exchange rates for each country versus the rest of the world.

The next step is to regress the relative dividend earnings and relative labor earnings on nominal exchange rates and take the residuals of this regression. This residual can be interpreted as that component of relative labor and capital income variability that cannot be diversified using nominal bonds, because it has been shown in the literature that most of the volatility of relative international real quantities (like the real exchange rate) is driven by fluctuations of nominal rates, and these risks can presumably be hedged using nominal bonds or currency forwards markets as in Engel and Matsumoto (2009). Thus the absence of bond holdings in the model will not lead it significantly astray, as has been shown by Coeurdacier and Gourinchas (2012), who conclude that what matters is the correlation of equity returns and non-financial income conditional on bond returns (or nominal exchange rates, since these are highly correlated). These residuals are used to calculate the covariance-variance ratio $R_{i}=\frac{\operatorname{cov}(\Delta \hat{\mathbb{L}}, \Delta \hat{D})}{\operatorname{var}(\Delta \hat{D})}$ in Proposition 3 for each country $i$ in the sample. Heathcote and Perri (2009) shows that $R_{i}$ is affected by the trade openness of

\footnotetext{
${ }^{30}$ Details are noted in the appendices.
} 

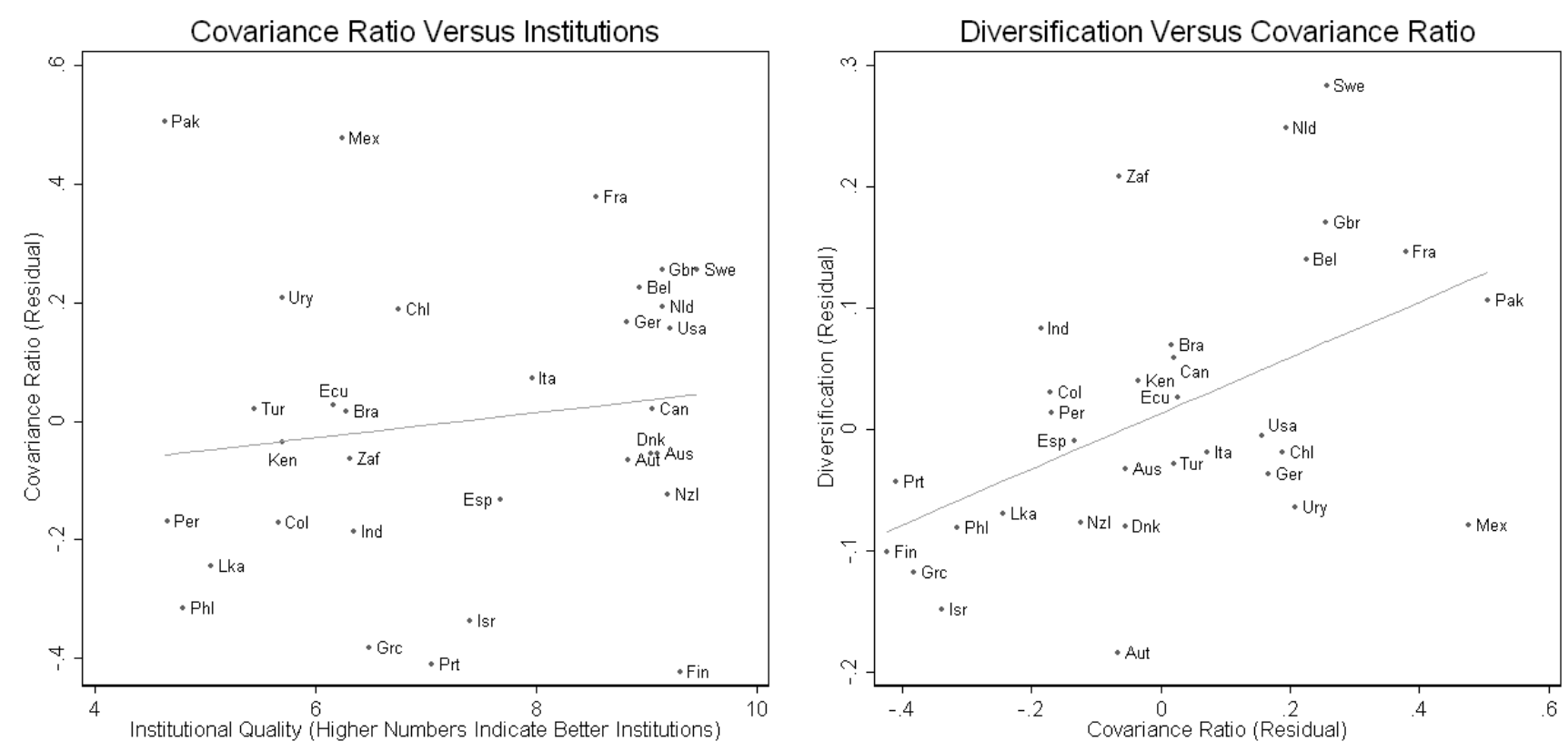

Figure 6: COVARIANCE RATIO, INSTITUTIONS AND DIVERSIFICATION. Notes: $R_{i}$ residuals on $\mathrm{y}$-axis in panel 1 and $\mathrm{x}$-axis of panel 2. International diversification on y-axis of panel 2. Diversification measure and covariance ratio $\left(R_{i}\right)$ residuals are author's construction, see text for details. Data source: WorldBank (2008), Lane and Milesi-Ferretti (2007), and LaPorta et al. (1998).

a country, something that can also be seen in the expression for $R_{i}$ in Lemma 2. Hence I regress $R_{i}$ on exports plus imports as a fraction of GDP, and use the residual from that regression as the empirical counterpart of $R_{i}$ in the analysis that follows. I call this variable ' $R_{i}$ residuals' henceforth.

The scatter plots above (Figure 6) show the $R_{i}$ residuals plotted against the LaPorta et al. (1998) index, and international diversification. International diversification in the scatter plot is the residual from a regression of foreign diversification (measured as the ratio of total foreign portfolio and FDI assets as a fraction of GDP), on a set of controls: exports plus imports as a fraction of GDP (trade openness), per capita GDP (general level of development), GDP (country size), and domestic credit as a fraction of GDP (financial development). ${ }^{31}$ The idea is that the $R_{i}$ residuals, by Lemma 1 , should be positively correlated with the part of international diversification that is not explained by its other well-known determinants. The pattern predicted by Lemmas 1 and 2 is confirmed in the data: In the first panel of the diagram below, countries with better institutional quality have a higher $R_{i}$, and in the second panel, those with higher $R_{i}$ are more diversified internationally.

Note, that we find that the calculated $R_{i}$ residuals are negative for 16 of the 32 countries. This is not surprising given that the data is annual and hence purged of a substantial portion of business cycle fluctuations. In fact, it is quite surprising that we find any pattern at all, because

\footnotetext{
${ }^{31}$ The results are identical when using foreign liabilities or the sum of foreign assets and liabilities.
} 
we have only 38 data points (years) per country on the basis of which the second moments could be calculated. However, it should also be noted here that recent studies such as Coeurdacier and Gourinchas (2012) and Heathcote and Perri (2009) have found using longer quarterly time series, albeit for fewer countries, that the empirical correlation of relative labor and dividend, conditional on bond returns, is negative. Thus my findings in conjunction with the existing literature suggests that the broad pattern predicted by the model holds in the data.

\section{Endogenous Insider Ownership}

The stylized facts presented in section 2 showed that insider ownership is higher on average in countries with lower institutional quality. ${ }^{32}$ The intuition as to why insider ownership in the South is high hinges on two forces. On the one hand, the insider being risk-averse desires to diversify internationally by lowering her ownership stake. However, lower ownership increases her incentive to extract private benefits of control. This reduces expected dividends for outsiders, thus lowering the market value of the domestic index. Outside investors take this into account, and hence are only willing to trade with the insider at lower prices for her holdings. ${ }^{33}$ This is the second force at work, an endogenous market-determined "transaction tax" on portfolio adjustments by insiders that penalizes diversification. In countries with low institutional quality, the second force dominates the first, leading to high insider ownership.

This section explores this effect quantitatively by enriching the asymmetric model with an analysis of the portfolio decision of the insider. In order to maintain tractability, I make a number of simplifying assumptions. First, I focus only on the insider's problem in the South while maintaining a fixed (low) level of insider ownership in the North. This reduces the computational burden of finding an equilibrium considerably while answering the crucial question as to what causes high and persistent insider ownership in Southern countries. It would be conceptually straightforward to extend the analysis to the case where insiders in both countries choose their ownership stakes. ${ }^{34}$ The second assumption is that the Southern insider trades in equity only once during the horizon of the model. This is a reasonable simplification in the light of two empirical observations. Kho et al. (2009) note that country level insider ownership shows little time variation. There is also ample evidence that insiders face large fixed costs of trading in their control blocks because of several factors such as asymmetric information between insiders and the market (Goldstein and Razin, 2006), price impacts of large share sales because of negatively sloped demand curve for

\footnotetext{
${ }^{32}$ Holderness (2009) has recently shown that earlier studies overestimate the degree of ownership diffusion in the United States. However, most studies concur that in an international cross section, countries with lower scores on measures of contract enforcement and corporate governance show higher insider ownership.

${ }^{33}$ Note that the insider takes into consideration the impact of her sale of shares on the price of these shares when deciding how much to sell. Thus the insider does not act as a price taker as in perfectly competitive markets.

${ }^{34}$ This would involve computing the best response function of each insider to the desired ownership of the other, $g: \alpha^{*} \rightarrow \alpha$ and $g^{*}: \alpha \rightarrow \alpha^{*}$ for the Northern and Southern insider respectively. The solution to the problem would then be the fixed point of the function $\left(g, g^{*}\right)$.
} 
assets (Shleifer, 1986; Chari and Henry, 2004), and the presence of private benefits of control (Nenova, 2003; Dyck and Zingales, 2004).

The economy starts at a steady state at $t=-1$ just prior to $t=0$. Insiders in each country start with a certain level of holdings in the two risky securities, Northern and Southern equity. Let this be $(\alpha, 0)$, for the Northern insider, so that she holds equity only in the North, and likewise, $\left(0, \alpha^{*}{ }_{-1}\right)$ for the Southern insider. The time-line is as follows. In period $t=-1$, the Southern insider announces desired holdings $\alpha_{S N}$ and $\alpha^{*}$ in the Northern and Southern stock index, for all time $t=0$ to $\infty$. Enforceable contracts are written between the Southern insider and outsiders in each country that she will sell $\left(\alpha^{*}{ }_{-1}-\alpha^{*}\right)$ units of Southern equity and will receive shares in the Northern stock index. Trade between the Southern insider and outsiders takes place at the real exchange rate and stock prices that prevail in the steady state corresponding to the final allocation of ownership. Since the insider is unable to commit to a certain level of valuereducing action because of weak corporate governance, the Southern stock price depends on the final holdings of the insider, $\alpha^{*}$, as in Admati et al. (1994) and DeMarzo and Urošević (2006), rather than the initial holdings $\alpha^{*}{ }_{-1}$. In period 0 , as agreed in the previous period's contract, $\alpha_{S N}=\frac{e^{s s} P^{* s s}\left(\alpha^{*}\right)}{P^{s s}(\alpha)}\left(\alpha^{*}-1-\alpha^{*}\right)$ units of the Northern stock index are delivered to the Southern insider. Also, trade takes place between outsiders and portfolio holdings $\left\{\lambda_{N N}, \lambda_{S N}, \lambda_{N S}, \lambda_{S S}\right\}$ are established. The Southern insider takes into account the effect her final holding has on the stock price, and consequently, her wealth, when she announces her desired holdings $\alpha^{*}$. At this stage she chooses $\alpha^{*}$ to maximize her discounted lifetime utility:

$$
\alpha^{*}=\operatorname{argmax}_{\alpha^{*^{\prime}}}\left\{V\left(\alpha^{*^{\prime}}, \cdot\right)\right\}
$$

where

$$
V\left(\alpha^{*^{\prime}}\right)=\max _{\left\{\mathrm{I}^{*}, \mathrm{D}^{*}, \mathrm{~L}^{*}, \mathrm{f}^{*}\right\}} \sum_{t=0}^{\infty} \sum_{s^{t}} Q^{*}\left(s^{t}\right)\left(\alpha^{*^{\prime}} D^{*}\left(s^{t}\right)+q_{b}\left(s^{t}\right) f^{*}\left(s^{t}\right) Y_{b}\left(s^{t}\right)-\Phi^{*}\left(s^{t}\right)+\alpha{ }_{S N} \frac{D\left(s^{t}\right)}{e\left(s^{t}\right)}\right)
$$

comes from the second stage maximization problem of the insider that was described in the earlier part of the paper, and $\alpha_{S N}=\frac{e^{s s} P^{* s s}\left(\alpha^{*^{\prime}}\right)}{P^{s s}(\alpha)}\left(\alpha_{-1}^{*}-\alpha^{*^{\prime}}\right)$. I evaluate the function $V$ for a fine grid of insider ownership stakes $\alpha^{*^{\prime}}$ by calculating the discounted sum of utility over 100 periods. This is done for a given amount of insider ownership in the North (20\%), the same as in the benchmark simulations for outsider portfolios before. This process is repeated over the 10 values of institutional quality, calibrated as before using the values for private benefits of control in Dyck and Zingales (2004). I describe the numerical algorithm in detail in the appendices.

Figure 7 below shows the Southern insider's lifetime utility thus calculated against a grid of ownership stakes and institutional quality. The x-axis shows the deciles of private benefits of control from left to right. Since lower private benefits correspond to better institutional quality, 0 on the $\mathrm{x}$-axis corresponds to high quality institutions in the South, with larger numbers denoting 
lower quality. The y-axis shows the different possible values of insider ownership in the South. The vertical axis shows expected lifetime utility of the Southern insider.

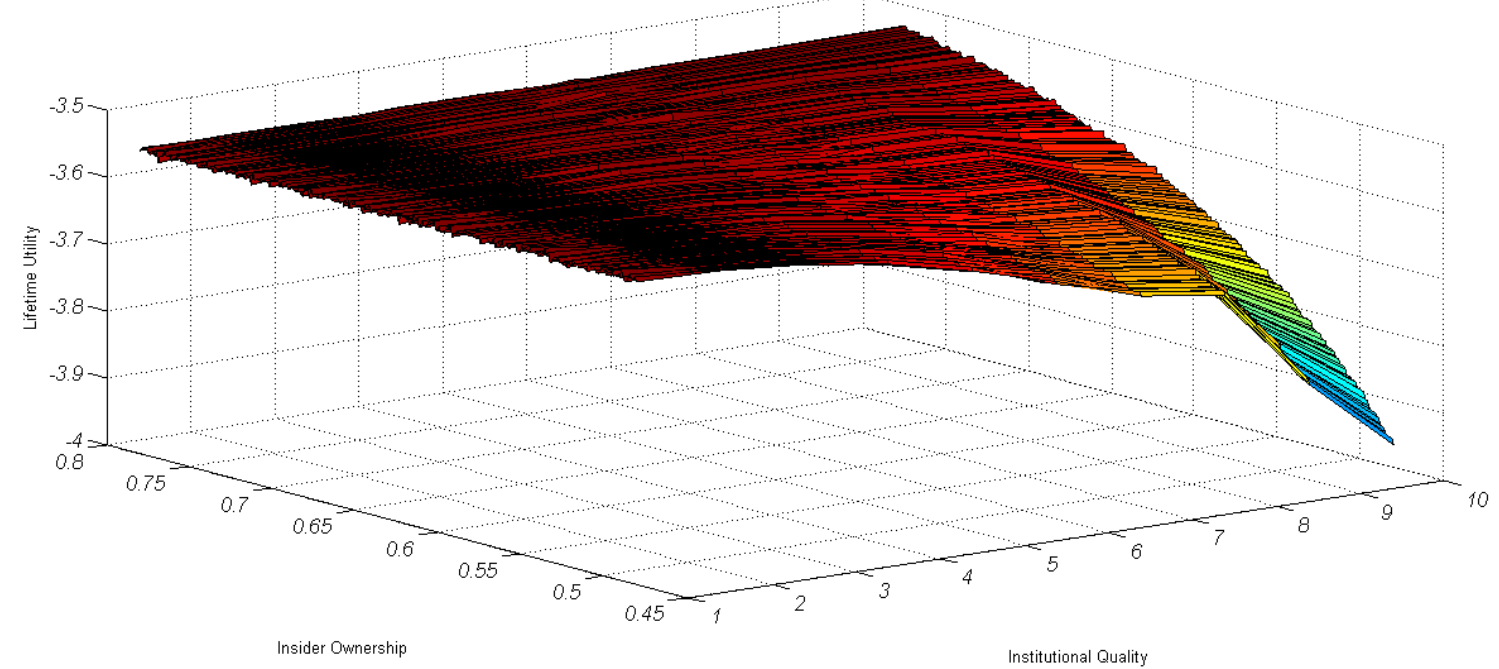

Figure 7: INSIDER'S EXPECTED LIFETIME UTILITY.

Notes: Institutional quality, measured by the deciles of private benefits, on the x-axis (lower numbers correspond to better institutions); insider ownership on the y-axis; insider lifetime expected utility on z-axis.

Figure 7 provides a quantitative demonstration of the intuition presented at the beginning of this section. For high levels of institutional quality, the lifetime utility of the Southern insider remains relatively flat as she reduces her holdings of the domestic asset. The reasons for this are as follows. When institutions in the South are of high quality, lower ownership stakes are not associated with lower dividends and equilibrium stock prices. Thus with good institutions, the insider's lifetime utility, at the margin, is determined only by the diversification benefits of owning foreign stock. These benefits happen to be rather small for our calibrated values of risk aversion and technological volatility. Recall that the insider in the benchmark calibration has log utility and is thus not very risk averse. As noted by van Wincoop (1999), the quantification of welfare gains from international diversification is extremely sensitive to the choice of a number of parameters. This is especially true for the degree of risk aversion and very high values of this parameter are usually necessary to find sizeable gains from diversification or realistic equity premia. Thus my finding is consistent with the large literature in international finance, surveyed in van Wincoop (1999), that finds relatively small utility gains from international diversification for similar calibrations. This is not surprising since the present model converges to the standard international real business cycle model when institutional quality in the South is perfect.

In contrast, when institutional quality is low, the lifetime utility of the insider drops off sharply when she diversifies. In this case, her ownership decision influences the Southern stock price at the margin, and hence worsens her asset "terms-of-trade" when she reduces her ownership: Outside 
investors, anticipating greater extraction of private benefits pay a lower price for stock and the Southern insider ends up with progressively smaller amounts of Northern cash flows rights in exchange for the marginal unit of Southern stock. This effect acts like an endogenous "transaction tax" on equity sales by the Southern insider. Thus the insider has no incentive to diversify in a country where poor corporate governance limits her ability to commit to actions that optimize firm value.

The insight that the portfolio of large shareholders is determined by their interaction with outside shareholders has long existed in the finance literature, exemplified by Admati et al. (1994) and DeMarzo and Urošević (2006). Both these papers study the asset allocation problem of a large shareholder who can affect the mean and volatility of security returns by expending costly private effort on monitoring. ${ }^{35}$ Effort being costly, the incentive to monitor comes from ownership of cash flow rights. Since the outsider can anticipate the rational choice of effort of the insider conditional on her ownership stake in the firm, the insider finds it costly to sell her shares: any reduction in stake, via a reduction in the incentive compatible level of monitoring effort, leads to a drop in share prices paid by the representative small investor. Admati et al. (1994) refer to this as a 'transaction tax', a phrase I borrow. However, their setup is closed-economy and partialequilibrium. The present paper, to best of my knowledge, is the first showing that this insight is also applicable to the determination of country-level insider ownership, and hence international capital flows.

\section{Conclusion}

I analyze the international portfolio diversification problem of small, security-only investors in the presence of insider ownership, corporate governance frictions, and non diversifiable labor income risk. This paper has four main contributions. First, it presents a fairly robust set of stylized facts about international equity portfolios, relating low institutional quality to higher insider ownership and low international diversification. Second, it shows that imperfect corporate governance influences the dynamics of investment in ways that makes equity in domestic firms a better hedge against fluctuations in labor income for residents in a country with poor institutions. This creates a preference for home assets in countries with poor institutions, a cross-sectional prediction that is consistent with empirical evidence presented in the paper. Third, the general equilibrium model is solved numerically for the optimal amount of insider equity to demonstrate the link between insider ownership and institutions on the one hand, and insider ownership and outsider portfolios on the other. Fourth, the paper provides cross sectional evidence that the main mechanism outlined in the paper holds in the data. The theoretical predictions of the model are also consistent with a wide range of empirical phenomenon such as the higher equity market volatility and lower

\footnotetext{
${ }^{35}$ Shleifer and Wolfenzon (2002) also show that better investor protection leads to more diffuse ownership of assets in a static, risk-neutral framework.
} 
stock prices in countries with weaker investor protection.

Recent work, exemplified by Caballero et al. (2008) and Mendoza et al. (2009) among others, has highlighted the role of the relative scarcity of high quality assets in the South in determining international capital flows. Furthermore, common sense tells us that domestic equity capital should flee from countries that have weaker institutions and hence a lower supply of safe assets. However, how much wealth is allocated to an asset depends not only on the variance of its payoff relative to other assets, but also on the covariance of this payoff with other sources of risk. The key insight of this is paper is that this covariance is intimately linked to domestic institutions and corporate governance. The analysis shows that while the traditional view of South-North capital flows is valid and is captured in the present model through the higher volatility of dividends in countries with weaker institutions, our understanding of capital flows between financial systems at different stages of development can be improved by taking into account non-securitizable risks such as labor income. Contrary to intuition, I find that domestic outside investors in countries with weaker institutions will hold more of their own country's float portfolio precisely because these have weaker institutions. The paper also applies insights from finance to highlight a possible mechanism driving aggregate insider ownership around the world, and argues that a number of features of the data, such as the volatility of investment, insider ownership and diversification, are driven by a common set of plausible agency friction within firms.

Though most of the stock of international assets is held by a handful of countries with similar, well-developed capital markets, nations where investor rights are relatively weak are playing an increasingly important role in international capital movements. Understanding how agency problems affect macroeconomic aggregates and portfolio allocation thus constitutes an important set of open questions that this paper tries to address. An extension of the work in this paper would seek to provide a fully dynamic framework for insider ownership that is better able to address questions about the time-path of country portfolios after financial liberalization and institutional reforms. Another promising avenue is to explore the effect of investment-specific technology shocks (Greenwood et al., 1997, 2000) in the framework of this paper, because such shocks are likely to magnify the investment-driven co-movements that are key to the results. These questions, and a richer empirical test of the mechanism by which the model generates home bias, perhaps using

more precise data on returns to equity, bond and human capital in emerging economies, is left for future work.

\section{References}

D. Acemoglu, S. Johnson, and J. A. Robinson. Reversal of fortune: Geography and institutions in the making of the modern world income distribution. Quarterly Journal of Economics, 117 (4):1231-1294, 2002. 
A. R. Admati, P. Pfleiderer, and J. Zechner. Large shareholder activism, risk sharing, and financial market equilibrium. The Journal of Political Economy, 102:1097-1130, 1994.

R. Albuquerque and E. J. Schroth. Quantifying private benefits of control from a structural model of block trades. Journal of Financial Economics, 96(1):33-55, 2010.

R. Albuquerque and N. Wang. Corporate governance and asset prices in a two-country model. Boston University and Columbia University working paper, 2006.

R. Albuquerque and N. Wang. Agency conflicts, investment, and asset pricing. The Journal of Finance, 63:1-40, 2008.

P. Antras and R. Caballero. Trade and capital flows: A financial frictions perspective. Journal of Political Economy, 117(4), 2009.

M. Barclay and C. Holderness. Private benefits from control of public corporations. Journal of financial Economics, 25(2), 1989.

M. Baxter and U. J. Jermann. The international diversification puzzle is worse than you think. The American Economic Review, 87:170-180, 1997.

F. Broner and J. Ventura. Rethinking the effects of financial liberalization. NBER Working Paper $16640,2010$.

F. Broner and J. Ventura. Globalization and risk sharing. Review of Economic Studies, 78(1): 49-82, 2011.

R. J. Caballero, E. Farhi, and P. O. Gourinchas. An equilibrium model of "global imbalances" and low interest rates. The American Economic Review, 98(1), 2008.

R. Castro, G. L. Clementi, and G. MacDonald. Investor protection, optimal incentives, and economic growth. The Quarterly Journal of Economics, 119(3), 2004.

A. Chari and P. B. Henry. Risk sharing and asset prices: Evidence from a natural experiment. The Journal of Finance, 59:1295-1324, 2004.

M. D. Chinn and H. Ito. A new measure of financial openness. Journal of Comparative Policy Analysis: Research and Practice, 10(3):309-322, 2008.

N. Coeurdacier. Do trade costs in goods market lead to home bias in equities? Journal of International Economics, 2008.

N. Coeurdacier and P. O. Gourinchas. When bonds matter: Home bias in goods and assets. Sciences-Po Working Paper, 2012. 
N. Coeurdacier, R. Kollmann, and P. Martin. International portfolios, capital accumulation and foreign assets dynamics. Journal of International Economics, 80(1):100-112, 2010.

H. L. Cole and M. Obstfeld. Commodity trade and international risk sharing. Journal of Monetary Economics, 28:3-24, 1991.

M. Dahlquist, L. Pinkowitz, R. Stulz, and R. Williamson. Corporate governance and the home bias. Journal of Financial and Quantitative Analysis, 38:87-110, 2003.

J. P. Danthine and J. B. Donaldson. Executive compensation: A general equilibrium perspective. Review of Economic Dynamics, forthcoming.

P. M. DeMarzo and B. Urošević. Ownership dynamics and asset pricing with a large shareholder. Journal of Political Economy, 114:774-815, 2006.

M. Devereux and A. Sutherland. Country portfolios in open economy macro-models. Journal of the European Economic Association, 9(2), 2011.

J. di Giovanni and A. Matsumoto. The value of human capital wealth. IMF Working Paper, 2012.

A. Dittmar, J. Mahrt-Smith, and H. Servaes. International corporate governance and corporate cash holdings. The Journal of Financial and Quantitative Analysis, 38(1):111-133, 2003.

S. Djankov, R. La Porta, F. Lopez-de Silanes, and A. Shleifer. The law and economics of selfdealing. Journal of Financial Economics, 88(3), 2008.

J. Dow, G. Gorton, and A. Krishnamurthy. Equilibrium investment and asset prices under imperfect corporate control. The American Economic Review, 95:659-681, 2005.

A. Dyck and L. Zingales. Private benefits of control: An international comparison. The Journal of Finance, 59(2), 2004.

C. Engel and A. Matsumoto. The international diversification puzzle when goods prices are sticky: It's really about exchange-rate hedging, not equity portfolios. American Economic Journal Macroeconomics, 1(2), 2009.

A. Faria and P. Mauro. Institutions and the external capital structure of countries. Journal of International Money and Finance, 28(3):367-391, 2009.

A. Faria, P. Mauro, P. Lane, and G. Milesi-Ferretti. The shifting composition of external liabilities. Journal of the European Economic Association, 5(2-3):480-490, 2007.

I. Goldstein and A. Razin. An information-based trade off between foreign direct investment and foreign portfolio investment. Journal of International Economics, 70:271-295, 2006. 
J. Greenwood, Z. Hercowitz, and P. Krusell. Long-run implications of investment-specific technological change. The American Economic Review, 1997.

J. Greenwood, Z. Hercowitz, and P. Krusell. The role of investment-specific technolical change in the business cycle. European Economic Review, 2000.

J. Heathcote and F. Perri. Financial globalization and real regionalization. Journal of Economic Theory, 119:207-243, 2004.

J. Heathcote and F. Perri. The international diversification puzzle is not as bad as you think. University of Minnesota and Federal Reserve Bank of Minneapolis Working Paper, 2009.

A. Heston, R. Summers, and B. Aten. Penn World Table Version 6.2. Center for International Comparisons of Production, Income and Prices at the University of Pennsylvania, September 2006 .

C. G. Holderness. The myth of diffuse ownership in the united states. Review of Financial Studies, 22(4):1377-1408, 2009.

M. C. Jensen. Agency costs of free cash flow. The American Economic Review, 76:323-329, 1986.

S. Kalemli-Ozcan, L. Alfaro, and V. Volosovych. Why doesn't capital flow from poor to rich countries? an empirical investigation. Review of Economics and Statistics, 90, 2008.

D. Kaufmann, A. Kraay, and M. Mastruzzi. Governance matters VII: aggregate and individual indicators, 1996-2007. World Bank Policy Research Paper, 4654, 2008.

B. C. Kho, R. M. Stulz, and F. E. Warnock. Financial globalisation, governance and the evolution of the home bias. Journal of Accounting Reasearch, 47:597-635, 2009.

E. H. Kim and A. Durnev. To steal or not to steal: Firm attributes, legal environment, and valuation. The Journal of Finance, 60:1461-1493, 2005.

A. Kraay, N. Loayza, L. Serven, and J. Ventura. Country portfolios. Journal of the European Economic Association, 3(4):914-945, 2005.

P. R. Lane and G. M. Milesi-Ferretti. The external wealth of nations mark ii: Revised and extended estimates of foreign assets and liabilities, 1970-2004. Journal of International Economics, 73: 223-250, 2007.

R. LaPorta, F. Lopez-De-Silanes, A. Shleifer, and R. W. Vishny. Legal determinants of external finance. The Journal of Finance, 52:1131-1150, 1997.

R. LaPorta, F. L. de Silanes, A. Shleifer, and R. W. Vishny. Law and finance. Journal of Political Economy, 106:1113-1155, 1998. 
R. LaPorta, F. L. de Silanes, and A. Shleifer. Corporate ownership around the world. Journal of Finance, 54:471-517, 1999.

R. LaPorta, F. L. de Silanes, A. Shleifer, and R. Vishny. Investor protection and corporate governance. Journal of Financial Economics, 58:3-27, 2000a.

R. LaPorta, F. L. de Silanes, A. Shleifer, and R. W. Vishny. Agency problems and dividend policies around the world. The Journal of Finance, 55:1-33, 2000b.

R. LaPorta, F. Lopez-De-Silanes, A. Shleifer, and R. Vishny. Investor protection and corporate valuation. The Journal of Finance, 57:1147-1170, 2002.

E. Mendoza, V. Quadrini, and J. Rios-Rull. Financial integration, financial development, and global imbalances. Journal of Political Economy, 117(3), 2009.

T. Nenova. The value of corporate voting rights and control: A cross-country analysis. Journal of Financial Economics, 68:325-351, 2003.

M. Obstfeld and K. Rogoff. The six major puzzles in international macroeconomics: Is there a common cause? NBER Macroeconomics Annual, 15:339-390, 2000.

T. Philippon. Corporate governance over the business cycle. Journal of Economic Dynamics and Control, 30:2117-2141, 2006.

S. Schmitt-Grohé and M. Uribe. Solving dynamic general equilibrium models using a second-order approximation to the policy function. Journal of Economic Dynamics and Control, 28:755-775, 2004 .

P. Sevcik. Financial contracts and the political economy of investor protection. American Economic Journal: Macroeconomics, 4(4), 2012.

A. Shleifer. Do demand curves for stocks slope down? Journal of Finance, 41:579-590, 1986.

A. Shleifer and D. Wolfenzon. Investor protection and equity markets. Journal of Financial Economics, 66:3-27, 2002.

C. Tille and E. Van Wincoop. International capital flows. Journal of International Economics, 80 (2), 2010 .

E. van Wincoop. How big are potential welfare gains from international risksharing? Journal of International Economics, 47:109-135, 1999.

E. van Wincoop and F. E. Warnock. Is home bias in assets related to home bias in goods? Journal of International Money and Finance, 29, 2010.

WorldBank. World development indicators. 2008. 


\section{A Appendices For Body of Paper}

\section{A.1 Proofs}

\section{A.1.1 Proof of Proposition 2}

The proof below follows Heathcote and Perri (2009) closely. The analytical solutions in this part of the appendix assume that: (a) the outsiders' utilities are separable between consumption and leisure and logarithmic in consumption; (b) the technology for combining intermediate goods to form the final consumption-investment good in each country is Cobb-Douglas and displays symmetric home bias; and (c) the two countries are ex-ante symmetric in that they have the same initial values of capital stock and technology, and the same stochastic driving shocks, and also symmetric in the sense that $\alpha=\alpha^{*}$ and $\eta=\eta^{*}$.

\section{Planner's Problem}

The social planner faces a static maximization problem at time $t$ after the realization of uncertainty. The Lagrangian at time $t$ maximized with respect to $\left\{C_{t}, C^{*}{ }_{t}, L_{t}, L^{*}{ }_{t}, a_{t}, a^{*}{ }_{t}, b_{t}, b^{*}{ }_{t}\right\}$ for each $\{t\}_{0}^{\infty}$ is as follows:

$$
\begin{array}{r}
L_{t}=\left[U\left(C_{t}, L_{t}\right)+U\left(C^{*}{ }_{t}, L^{*}{ }_{t}\right)+\lambda_{a t}\left(A_{t} K_{t}{ }^{\alpha} L_{t}{ }^{1-\alpha}-a_{t}-a^{*}{ }_{t}\right)+\lambda_{b t}\left(A^{*}{ }_{t} K^{*}{ }_{t}{ }^{\alpha} L^{*}{ }_{t}{ }^{1-\alpha}-b_{t}-b^{*}{ }_{t}\right)\right. \\
\left.+\lambda_{H t}\left(G\left(a_{t}, b_{t}\right)-C_{t}-I_{t}-M_{t}-\Phi_{t}\right)+\lambda_{F t}\left(G^{*}\left(a^{*}{ }_{t}, b^{*}{ }_{t}\right)-C^{*}{ }_{t}-I^{*}{ }_{t}-M^{*}{ }_{t}-\Phi^{*}{ }_{t}\right)\right]
\end{array}
$$

Since the first order conditions of the planner's problem are all static, the time subscripts are dropped for notational simplicity.

$$
\begin{aligned}
U_{C} & =\lambda_{H} \\
U_{C^{*}} & =\lambda_{F} \\
U_{L}+\lambda_{a}(1-\alpha) A K^{\alpha} L^{-\alpha} & =0 \\
U_{L^{*}}+\lambda_{b}(1-\alpha) A^{*} K^{* \alpha} L^{*-\alpha} & =0 \\
\lambda_{a} & =\lambda_{H} G_{a} \\
\lambda_{b} & =\lambda_{H} G_{b} \\
\lambda_{a} & =\lambda_{F} G^{*} a^{*} \\
\lambda_{b} & =\lambda_{F} G^{*} b^{*}
\end{aligned}
$$

The planner takes the optimality conditions arising out of the insiders' problems (listed in the paper) as given each time $t$. To prove that the equilibrium described in Proposition 2 exists, we show that the planner's allocation can be decentralized under certain prices using just the two equity shares under the assumptions on functional forms noted above, and that these prices are 
also consistent with the optimality conditions for the insiders' behavior. Let goods prices be given by:

$$
\begin{aligned}
q_{a} & =\frac{\omega G}{a} \\
q_{b} & =\frac{(1-\omega) G}{b} \\
q_{a^{*}} & =\frac{(1-\omega) G^{*}}{a^{*}} \\
q_{b^{*}} & =\frac{\omega G^{*}}{b^{*}} \\
e & =\frac{q_{a}}{q_{a^{*}}}=\frac{q_{b}}{q_{b^{*}}}
\end{aligned}
$$

The prices $\left\{q_{a}, q_{b}, q_{a^{*}}, q_{b^{*}}\right\}$ ensure that intermediate goods are used optimally in the stock trade economy.

$$
\begin{aligned}
W & =(1-\theta)\left(1+\frac{(1-\alpha)^{2}}{2 \alpha \eta}\right) \frac{Y_{a}}{L_{t}} \\
W^{*} & =(1-\theta)\left(1+\frac{(1-\alpha)^{2}}{2 \alpha \eta}\right) \frac{Y_{b}}{L^{*}}
\end{aligned}
$$

These wages ensure that the labor demand optimality conditions from insiders is satisfied. Also substituting the above prices into the planner's optimality conditions for labor usage gives us back the optimal labor supply conditions of the outsiders. Note that the resource constraints for the planner's problem and the stock market equilibrium posited are identical. Also, stock market clearing is trivial by the symmetry of the portfolio shares.

\section{Construction of the Portfolio Share $\lambda$}

In the following part I deliberately keep the state notation to emphasize that the portfolio shares constructed ensure risk sharing for each state of nature under the functional form assumptions. Consider the budget constraints of the outsiders in the two countries. With time invariant optimal portfolio shares the budget constraints reduce to

$$
\begin{gathered}
C\left(s^{t}\right)=q_{a}\left(s^{t}\right) W\left(s^{t}\right) L\left(s^{t}\right)+\lambda_{N N} D\left(s^{t}\right)+\lambda_{N S} e\left(s^{t}\right) D^{*}\left(s^{t}\right) \\
C^{*}\left(s^{t}\right)=q_{b}\left(s^{t}\right) W^{*}\left(s^{t}\right) L^{*}\left(s^{t}\right)+\frac{\lambda_{S N} D\left(s^{t}\right)}{e\left(s^{t}\right)}+\lambda_{S S} D^{*}\left(s^{t}\right)
\end{gathered}
$$

Note that these are free of the stock prices $P\left(s^{t}\right)$ and $P^{*}\left(s^{t}\right)$. Using the candidate expression for 
wages, and the optimal fraction of private benefits from the insiders' problem,

$$
\begin{aligned}
W\left(s^{t}\right) L\left(s^{t}\right) & =\frac{1-\theta}{\alpha}\left(\alpha+\frac{(1-\alpha)^{2}}{2 \eta}\right) Y_{a}\left(s^{t}\right) \\
W^{*}\left(s^{t}\right) L^{*}\left(s^{t}\right) & =\frac{1-\theta}{\alpha}\left(\alpha+\frac{(1-\alpha)^{2}}{2 \eta}\right) Y_{b}\left(s^{t}\right) \\
f\left(s^{t}\right) & =\frac{1-\alpha}{\eta} \\
f^{*}\left(s^{t}\right) & =\frac{1-\alpha}{\eta}
\end{aligned}
$$

dividends can be written as

$$
\begin{aligned}
D\left(s^{t}\right) & =q_{a}\left(s^{t}\right) Y_{a}\left(s^{t}\right)\left[\psi_{1}-\psi_{0}\right]-I\left(s^{t}\right) \\
D^{*}\left(s^{t}\right) & =q_{b}\left(s^{t}\right) Y_{b}\left(s^{t}\right)\left[\left[\psi_{1}-\psi_{0}\right]\right]-I^{*}\left(s^{t}\right)
\end{aligned}
$$

where $\psi_{0}=(1-\theta)\left\{1+\frac{(1-\alpha)^{2}}{2 \alpha \eta}\right\}$ and $\psi_{1}=\frac{\eta+\alpha-1}{\eta}$.

Thus the budget constraints reduce to

$$
\begin{aligned}
C\left(s^{t}\right) & =\psi_{0} y\left(s^{t}\right)+\lambda_{N N}\left[\left(\psi_{1}-\psi_{0}\right) y\left(s^{t}\right)-I\left(s^{t}\right)\right]+\lambda_{N S} e\left(s^{t}\right)\left[\left(\psi_{1}-\psi_{0}\right) y^{*}\left(s^{t}\right)-I^{*}\left(s^{t}\right)\right] \\
C^{*}\left(s^{t}\right) & =\psi_{0} y^{*}\left(s^{t}\right)+\frac{\lambda_{S N}}{e\left(s^{t}\right)}\left[\left(\psi_{1}-\psi_{0}\right) y\left(s^{t}\right)-I\left(s^{t}\right)\right]+\lambda_{S S}\left[\left(\psi_{1}-\psi_{0}\right) y^{*}\left(s^{t}\right)-I^{*}\left(s^{t}\right)\right] .
\end{aligned}
$$

With logarithmic utility, the planner's constrained (by the insiders' socially sub-optimal decisions) Pareto efficient consumption allocations follow

$$
C\left(s^{t}\right)=e\left(s^{t}\right) C^{*}\left(s^{t}\right)
$$

This can be seen from combining conditions 7.6 - 7.9 of the planner's problem and using the expression for the real exchange rate posited before. Therefore we need to construct portfolio shares such that the above condition holds, while being consistent with the insiders' optimality conditions and the posited prices. If there exists a portfolio share $\lambda$ such that this condition holds for all states, then $\lambda$ must satisfy

$C\left(s^{t}\right)-e\left(s^{t}\right) C^{*}\left(s^{t}\right)=\left[\psi_{0}+\left(\psi_{1}-\psi_{0}\right)(2 \lambda+\alpha-1)\right]\left\{y\left(s^{t}\right)-e\left(s^{t}\right) y^{*}\left(s^{t}\right)\right\}-(2 \lambda+\alpha-1)\left\{I\left(s^{t}\right)-e\left(s^{t}\right) I^{*}\left(s^{t}\right)\right\}=0$

where I have expressed all portfolio shares in terms of $\lambda$ by using symmetry and market clearing in asset markets, which imply that $\lambda_{N N}=\lambda_{S S}=\lambda$ and $\lambda_{S N}=\lambda_{N S}=1-\alpha-\lambda$.

Now, $y\left(s^{t}\right)=q_{a}\left(s^{t}\right) Y_{a}\left(s^{t}\right)=q_{a}\left(s^{t}\right)\left\{a\left(s^{t}\right)+a^{*}\left(s^{t}\right)\right\}=\omega Y\left(s^{t}\right)+(1-\omega) e\left(s^{t}\right) Y^{*}\left(s^{t}\right)$ and $y^{*}\left(s^{t}\right)=$ $\left.q_{b}\left(s^{t}\right) Y_{b}\left(s^{t}\right)=q_{b}\left(s^{t}\right)\left\{b\left(s^{t}\right)+b^{*}\left(s^{t}\right)\right\}=(1-\omega) \frac{Y\left(s^{t}\right)}{e\left(s^{t}\right)}+\omega Y^{*}\left(s^{t}\right)\right\}$. Henceforth for all variables $x$, 
$\Delta x\left(s^{t}\right)$ denotes the value of $x\left(s^{t}\right)-e\left(s^{t}\right) x^{*}\left(s^{t}\right)$. Therefore

$$
\begin{aligned}
\Delta y\left(s^{t}\right) & =y\left(s^{t}\right)-e\left(s^{t}\right) y^{*}\left(s^{t}\right) \\
& =(2 \omega-1)\left\{Y\left(s^{t}\right)-e\left(s^{t}\right) Y^{*}\left(s^{t}\right)\right\} \\
& =(2 \omega-1) \Delta Y\left(s^{t}\right)
\end{aligned}
$$

Using the final-goods market-clearing conditions and the expression for the insiders' consumption demand

$$
\begin{aligned}
Y\left(s^{t}\right) & =C\left(s^{t}\right)+K\left(s^{t}\right)-(1-\delta) K\left(s^{t-1}\right)+M\left(s^{t}\right)+\Phi\left(s^{t}\right) \\
Y^{*}\left(s^{t}\right) & =C_{m^{*}}\left(s^{t}\right)+K^{*}\left(s^{t}\right)-(1-\delta) K^{*}\left(s^{t-1}\right)+M^{*}\left(s^{t}\right)+\Phi^{*}\left(s^{t}\right) \\
M\left(s^{t}\right) & =\alpha D\left(s^{t}\right)+q_{a}\left(s^{t}\right) f\left(s^{t}\right) Y_{a}\left(s^{t}\right)-\Phi\left(s^{t}\right) \\
M^{*}\left(s^{t}\right) & =\alpha D^{*}\left(s^{t}\right)+q_{b}\left(s^{t}\right) f^{*}\left(s^{t}\right) Y_{b}\left(s^{t}\right)-\Phi^{*}\left(s^{t}\right)
\end{aligned}
$$

together with the expressions for the optimal stealing fraction and dividends, we have

$$
\begin{aligned}
\Delta y\left(s^{t}\right) & =(2 \omega-1) \Delta Y\left(s^{t}\right) \\
& =(2 \omega-1)\left[\Delta C\left(s^{t}\right)+\Delta I\left(s^{t}\right)+\left\{\alpha \theta+\frac{(1+\theta)(1-\alpha)^{2}}{2 \eta}\right\} \Delta y\left(s^{t}\right)-\alpha \Delta I\left(s^{t}\right)\right]
\end{aligned}
$$

This gives after some algebra

$$
\Delta y\left(s^{t}\right)=\frac{(2 \omega-1)}{\psi_{2}}\left\{\Delta C\left(s^{t}\right)+(1-\alpha) \Delta I\left(s^{t}\right)\right\}
$$

where

$$
\psi_{2}=1-(2 \omega-1)\left\{\alpha \theta+\frac{(1+\theta)(1-\alpha)^{2}}{2 \eta}\right\}
$$

Now, plugging in the value of $\Delta y\left(s^{t}\right)$ in the expression for $\Delta C\left(s^{t}\right)$, we get, for some constant $\mu$

$$
\mu \Delta C\left(s^{t}\right)=\left[\psi_{2}^{-1}(1-\alpha)(2 \omega-1)\left\{\psi_{0}+\left(\psi_{1}-\psi_{0}\right)(2 \lambda+\alpha-1)\right\}-(2 \lambda+\alpha-1)\right] \Delta I\left(s^{t}\right)
$$

This expression gives us the value of the portfolio share, $\lambda$, that will ensure that the complete markets condition, $\Delta C\left(s^{t}\right)=0$, holds for all states. The value of $\lambda$ is calculated by simply assuming this the condition holds, and then solving for $\lambda$ and this is the $\lambda$ stated in Proposition 2. Thus by construction $\lambda$ satisfies the optimal consumption allocations of the planner's problem and satisfies the outsiders' optimality conditions and the budget constraints of the outsider of the stock trade economy. Now note that by construction, the stock prices below satisfy the four first 
order conditions of the outsiders' stock purchases.

$$
\begin{aligned}
P_{t} & =\mathrm{E}_{\mathrm{t}} \sum_{s=0}^{\infty} \beta^{t} \frac{U_{C}\left(C_{s+t+1}\right)}{U_{C}\left(C_{t}\right)} D_{s+t+1} \\
P^{*}{ }_{t} & =\mathrm{E}_{\mathrm{t}} \sum_{s=0}^{\infty} \beta^{t} \frac{U_{C^{*}}\left(C^{*}{ }_{s+t+1}\right)}{U_{C^{*}}\left(C^{*}{ }_{t}\right)} \frac{e_{t+1}}{e_{t}} D^{*}{ }_{s+t+1}
\end{aligned}
$$

This completes the proof of Proposition 2 in section (4.2).

\section{A.1.2 Proof of Lemma 1}

Plugging in $C\left(s^{t}\right)=q_{a}\left(s^{t}\right) W\left(s^{t}\right) L\left(s^{t}\right)+\lambda_{N N} D\left(s^{t}\right)+\lambda_{N S} e\left(s^{t}\right) D^{*}\left(s^{t}\right)$ and $C^{*}\left(s^{t}\right)=q_{b}\left(s^{t}\right) W^{*}\left(s^{t}\right) L^{*}\left(s^{t}\right)$ $+\frac{\lambda_{S N} D\left(s^{t}\right)}{e\left(s^{t}\right)}+\lambda_{S S} D^{*}\left(s^{t}\right)$ into $C\left(s^{t}\right)=e\left(s^{t}\right) C^{*}\left(s^{t}\right)$ and denoting $q_{a}\left(s^{t}\right) W\left(s^{t}\right) L\left(s^{t}\right)$ by $\mathbb{L}$ and $q_{b}\left(s^{t}\right) W^{*}\left(s^{t}\right) L^{*}\left(s^{t}\right)$ by $\mathbb{L}^{*}$, we get upon log-linearizing around the symmetric steady-state,

$\overline{\mathbb{L}} \hat{\mathbb{L}}+\bar{D} \hat{D} \lambda+\bar{e} \bar{D}^{*} \hat{D}^{*}(1-\alpha-\lambda)+\bar{e} \bar{D}^{*} \hat{e}(1-\alpha-\lambda) \approx \bar{e} \overline{\mathbb{L}}^{*} \overline{\mathbb{L}}^{*}+\bar{e} \overline{\mathbb{L}}^{-} \hat{e}+\bar{D} \hat{D}(1-\alpha-\lambda)+\bar{e} \bar{D}^{*} \hat{D}^{*} \lambda+\bar{e} \bar{D}^{*} \hat{e} \lambda$

Gathering terms and noting that $\bar{D}^{*}=\bar{D}, \bar{L}^{*}=\bar{L}, \bar{e}=1$ in a symmetric equilibrium we get

$$
(1-\alpha-2 \lambda) \bar{D}\left(\hat{D}-\hat{e}-\hat{D}^{*}\right) \approx \overline{\mathbb{L}}\left(\hat{\mathbb{L}}-\hat{e}-\hat{\mathbb{L}}^{*}\right)
$$

Denoting $\left(\hat{D}-\hat{e}-\hat{D}^{*}\right)$ as $\Delta \hat{D}$ and $\left(\hat{\mathbb{L}}-\hat{e}-\hat{\mathbb{L}}^{*}\right)$ as $\Delta \hat{\mathbb{L}}$ we get

$$
(1-\alpha-2 \lambda) \bar{D} \Delta \hat{D} \approx \overline{\mathbb{L}} \Delta \hat{\mathbb{L}}
$$

which gives,

$$
(2 \lambda+\alpha-1) \approx-\frac{\overline{\mathbb{L}}}{\bar{D}} \frac{\operatorname{cov}(\Delta \hat{\mathbb{L}}, \Delta \hat{D})}{\operatorname{var}(\Delta \hat{D})}
$$

Solving for $\lambda$ gives the result. 


\section{A.2 Empirical Evidence}

\begin{tabular}{|c|c|c|c|c|c|c|c|}
\hline & $(1)$ & $(2)$ & $(3)$ & (4) & $(5)$ & (6) & (7) \\
\hline La Porta Index & $\begin{array}{l}0.153^{* * *} \\
(0.03)\end{array}$ & $\begin{array}{l}0.173^{* * * *} \\
(0.03)\end{array}$ & $\begin{array}{l}0.206^{* * * *} \\
(0.06)\end{array}$ & $\begin{array}{l}0.128^{* *} \\
(0.05)\end{array}$ & $\begin{array}{l}0.160^{* * * *} \\
(0.04)\end{array}$ & $\begin{array}{l}0.158^{* * * *} \\
(0.04)\end{array}$ & $\begin{array}{l}0.122^{* * *} \\
(0.04)\end{array}$ \\
\hline GDP & & $\begin{array}{l}-0.058^{* *} \\
(0.03)\end{array}$ & $\begin{array}{l}-0.050^{*} \\
(0.03)\end{array}$ & $\begin{array}{c}-0.016 \\
(0.02)\end{array}$ & $\begin{array}{l}0.003 \\
(0.02)\end{array}$ & $\begin{array}{l}0.003 \\
(0.02)\end{array}$ & $\begin{array}{l}-0.010 \\
(0.02)\end{array}$ \\
\hline P.C. GDP & & & $\begin{array}{l}-0.006 \\
(0.01)\end{array}$ & $\begin{array}{l}-0.000 \\
(0.01)\end{array}$ & $\begin{array}{l}-0.002 \\
(0.01)\end{array}$ & $\begin{array}{l}-0.003 \\
(0.01)\end{array}$ & $\begin{array}{l}-0.007 \\
(0.01)\end{array}$ \\
\hline Trade Openness & & & & $\begin{array}{l}0.003^{* * *} \\
(0.00)\end{array}$ & $\begin{array}{l}0.004^{* * *} \\
(0.00)\end{array}$ & $\begin{array}{l}0.004^{* * *} \\
(0.00)\end{array}$ & $\begin{array}{l}0.004^{* * *} \\
(0.00)\end{array}$ \\
\hline Fin. Dev. & & & & & $\begin{array}{l}-0.001 \\
(0.00)\end{array}$ & $\begin{array}{l}-0.001 \\
(0.00)\end{array}$ & $\begin{array}{c}-0.002 \\
(0.00)\end{array}$ \\
\hline Fin. Openness & & & & & & $\begin{array}{l}0.012 \\
(0.03)\end{array}$ & $\begin{array}{l}0.050 \\
(0.04)\end{array}$ \\
\hline Ownership Conc. & & & & & & & $\begin{array}{l}-0.984^{* * *} \\
(0.32)\end{array}$ \\
\hline Constant & $\begin{array}{l}-0.729^{* * *} \\
(0.18)\end{array}$ & $\begin{array}{l}-0.833^{* * *} \\
(0.20)\end{array}$ & $\begin{array}{l}-1.008^{* * *} \\
(0.33)\end{array}$ & $\begin{array}{l}-0.775^{* *} \\
(0.30)\end{array}$ & $\begin{array}{l}-0.899^{* * *} \\
(0.25)\end{array}$ & $\begin{array}{l}-0.890^{* * *} \\
(0.25)\end{array}$ & $\begin{array}{l}-0.117 \\
(0.31)\end{array}$ \\
\hline $\mathrm{N}$ & 37 & 37 & 37 & 37 & 37 & 37 & 37 \\
\hline Adjusted $R^{2}$ & 0.401 & 0.447 & 0.436 & 0.711 & 0.718 & 0.709 & 0.762 \\
\hline
\end{tabular}

Notes: Point estimates of regression coefficients with heteroscedasticity-robust standard errors in brackets. Specifications (1), (2), (3), (4), (5), (6) and (7), are all with a constant term, consecutively add the regressors mentioned in the first column. Coefficients marked $* * *$, **, and * are significant at 1\%,5\%, and 10\% respectively. Dependent variable: international diversification measured by total foreign portfolio and FDI assets and liabilities as a fraction of GDP. Independent variables: Institutional quality index is the simple average the indices from LaPorta et al. (1998) which measure the rule of law, risk of contract repudiation and expropriation, accounting standards, and efficacy of the judicial system ; GDP in trillions of USD; per capita GDP in thousands of USD; trade as percentage of GDP; domestic credit to private sector as percentage of GDP; Chinn and Ito (2008) measure of capital account openness; ownership concentration from Djankov et al. (2008). 


\section{B APPENDICES FOR ONLINE PUBLICATION}

\section{B.1 Data}

\section{B.1.1 Data Sources}

Lane and Milesi-Ferretti (2007) for external wealth (145 countries, 1970-2004); Heston et al. (2006) for capital stock, investment (188 countries, 1950-2004); Kho et al. (2009) for insider ownership (46 countries, 1994 and 2004) ; LaPorta et al. (1998) for corporate governance indices (49 countries); Kaufmann et al. (2008) for institutional quality (212 countries, 1996-2007); WorldBank (2008) for trade, GDP, financial development, fixed capital formation, nominal exchange rates (variable years and countries).

\section{B.1.2 Samples}

Sample 1: Intersection of set of countries used in LaPorta et al. (1998), and covered by WorldBank (2008), excluding financial centers Ireland and Switzerland (total FA + FL > 150\% of GDP). 43 countries are: Argentina, Australia, Austria, Belgium, Brazil, Canada, Chile, Colombia, Denmark, Ecuador, Egypt, Finland, France, Germany, Greece, India, Indonesia, Israel, Italy, Japan, Jordan, Kenya, Malaysia, Mexico, Netherlands, New Zealand, Nigeria, Norway, Pakistan, Peru, Philippines, Portugal, Singapore, South Africa, Spain, Sri Lanka, Sweden, Thailand, Turkey, United Kingdom, United States, Uruguay and Zimbabwe. See LaPorta et al. (1998) for sample selection criteria. Used for constructing Figure 1 in stylized facts section and for asset regression in appendix.

Sample 2: Intersection of set of countries used in Kho et al. (2009), and covered by WorldBank (2008), excluding financial centers Ireland, Luxembourg and Switzerland (total FA + FL > 150\% of GDP). 34 countries, subset of Sample 1 (excluding italicized countries) above but includes Poland. Used for constructing Figure 2 in stylized facts section, and to test if worse institutions affect portfolios primarily through increasing insider ownership and decreasing the float portfolio.

Sample 3: Sample 1, excluding Argentina, Indonesia, Jordan, Nigeria (gaps in fixed capital investment data) and Zimbabwe (hyperinflation towards the end of the sample period), and 6 countries for which constructed dividends are negative (Egypt, Japan, Malaysia, Norway, Singapore, Thailand). 32 countries. Sample period is 1970-2007 because of gaps in the data prior to 1970 and the financial crisis starting 2008. Used to test the theoretical mechanisms predicted by the model. 


\section{B.2 Steady State Values}

\section{B.2.1 The Steady-State with Symmetric Countries}

If the countries are ex-ante symmetric, $\eta=\eta^{*}=\bar{\eta}, \alpha=\alpha^{*}=\bar{\alpha}, \psi_{0}=\psi_{0}^{*}=\bar{\psi}_{0}$, and $\psi_{1}=\psi^{*}{ }_{1}=\bar{\psi}_{1}$. The non-stochastic steady-state values of capital stocks $K^{s s}$ and $K^{* s s}$ can be expressed in terms of $L^{s s}=L^{* s s}=\bar{L}^{s s}$ and $q_{a}^{s s}=q_{a}^{* s s}=q_{b}^{s s}=q_{b}^{* s s}=q^{\bar{s} s}$. The actual expression for $q^{\bar{s} s}$ is given later.

$$
\begin{aligned}
K^{s s} & =\left[\frac{\theta}{1-\theta} \frac{\bar{\psi}_{0} q_{a}^{s s}}{\frac{1}{\beta}+\delta-1}\right]^{\frac{1}{1-\theta}} \bar{L}^{s s}=\left[\frac{\theta}{1-\theta} \frac{\overline{\psi_{0}} q^{\bar{s}}}{\frac{1}{\beta}+\delta-1}\right]^{\frac{1}{1-\theta}} \bar{L}^{-s} \\
K^{* s s} & =\left[\frac{\theta}{1-\theta} \frac{\overline{\psi_{0}} q_{b}^{* s s}}{\frac{1}{\beta}+\delta-1}\right]^{\frac{1}{1-\theta}} \bar{L}^{-s s}=\left[\frac{\theta}{1-\theta} \frac{\overline{\psi_{0}} q^{\bar{s} s}}{\frac{1}{\beta}+\delta-1}\right]^{\frac{1}{1-\theta}} L^{-} s
\end{aligned}
$$

The other aggregate quantities, which can also be expressed in terms of $L^{s s}=L^{* s s}=\overline{L^{s s}}$ and $q^{\bar{s} s}$, are as follows. Note that these depend on the institution-related parameters $\bar{\alpha}$ and $\bar{\eta}$ only through $K^{s s}$ and $K^{* s s}$.

$$
\begin{aligned}
& Y_{a}^{s s}=K^{s s \theta} \overline{L^{s s}}{ }^{1-\theta}=\left(\frac{K^{s s}}{\bar{L}^{s s}}\right)^{\theta} \overline{L^{s s}}=\left[\frac{\theta}{1-\theta} \frac{\overline{\psi_{0}} q^{\bar{s} s}}{\frac{1}{\beta}+\delta-1}\right]^{\frac{\theta}{1-\theta}} \overline{L^{s s}} \\
& Y_{b}^{s s}=K^{* s s \theta}{\overline{L^{s s}}}^{1-\theta}=\left(\frac{K^{* s s}}{\overline{L^{s} s}}\right)^{\theta} \overline{L^{s s}}=\left[\frac{\theta}{1-\theta} \frac{\overline{\psi_{0}} q^{\bar{s} s}}{\frac{1}{\beta}+\delta-1}\right]^{\frac{\theta}{1-\theta}} \overline{L^{s s}} \\
& Y^{s s}=q_{a}^{s s} Y_{a}^{s s}=q^{\overline{s s}}\left[\frac{\theta}{1-\theta} \frac{\overline{\psi_{0}} q^{\bar{s} s}}{\frac{1}{\beta}+\delta-1}\right]^{\frac{\theta}{1-\theta}} \overline{L^{s s}} \\
& Y^{* s s}=q_{b}^{* s s} Y_{b}^{s s}=q^{\overline{s s}}\left[\frac{\theta}{1-\theta} \frac{\bar{\psi}_{0} q^{\bar{s} s}}{\frac{1}{\beta}+\delta-1}\right]^{\frac{\theta}{1-\theta}} L^{-} s \\
& q_{a}^{s s} a^{s s}=\omega Y^{s s} \Rightarrow a^{s s}=\omega Y_{a}^{s s}=\omega\left[\frac{\theta}{1-\theta} \frac{\overline{\psi_{0}} q^{\bar{s} s}}{\frac{1}{\beta}+\delta-1}\right]^{\frac{\theta}{1-\theta}} \bar{L}^{-s} \\
& a^{s s}+a^{* s s}=Y_{a}^{s s} \Rightarrow a^{* s s}=(1-\omega) Y_{a}^{s s}=(1-\omega)\left[\frac{\theta}{1-\theta} \frac{\overline{\psi_{0}} q^{\overline{s s}}}{\frac{1}{\beta}+\delta-1}\right]^{\frac{\theta}{1-\theta}} L^{-} \\
& q_{b}^{* s s} b^{* s s}=\omega Y^{* s s} \Rightarrow b^{* s s}=\omega Y_{b}^{s s}=\omega\left[\frac{\theta}{1-\theta} \frac{\overline{\psi_{0}} q^{\bar{s} s}}{\frac{1}{\beta}+\delta-1}\right]^{\frac{\theta}{1-\theta}} \overline{L^{s s}} \\
& b^{s s}+b^{* s s}=Y_{a}^{s s} \Rightarrow b^{s s}=(1-\omega) Y_{b}^{s s}=(1-\omega)\left[\frac{\theta}{1-\theta} \frac{\overline{\psi_{0}} q^{\bar{s} s}}{\frac{1}{\beta}+\delta-1}\right]^{\frac{\theta}{1-\theta}} \bar{L}^{-}
\end{aligned}
$$

If $G(a, b)=a^{\omega} b^{1-\omega}$, then $q_{a}^{s s}, q_{a}^{* s s}, q_{b}^{s s}$, and $q_{b}^{* s s}$ are given by

$$
q_{a}^{s s}=q_{a}^{* s s}=q_{b}^{s s}=q_{b}^{* s s}=\omega^{\omega}(1-\omega)^{1-\omega}=q^{\bar{s} s}
$$


which implies

$$
\begin{gathered}
e^{s s}=1 \\
t^{s s}=1 .
\end{gathered}
$$

The following quantities reflect the distribution of aggregate final output among various sources of absorbtion with the economy and are affected by the institution-related parameters $\bar{\alpha}$ and $\bar{\eta}$ independently of $K^{s s}$ and $K^{* s s}$, of which they are also functions.

$$
\begin{aligned}
& D^{s s}=\left[\frac{(1-\theta)}{\theta} \frac{\left(\bar{\psi}_{1}-\bar{\psi}_{0}\right)}{\bar{\psi}_{0}}\left(\frac{1}{\beta}+\delta-1\right)-\delta\right] K^{s s} \\
& =\left[\frac{(1-\theta)}{\theta} \frac{\left(\bar{\psi}_{1}-\bar{\psi}_{0}\right)}{\bar{\psi}_{0}}\left(\frac{1}{\beta}+\delta-1\right)-\delta\right]\left[\frac{\theta}{1-\theta} \frac{\bar{\psi}_{0} q^{\bar{s} s}}{\frac{1}{\beta}+\delta-1}\right]^{\frac{1}{1-\theta}} \overline{L^{s s}} \\
& D^{* s s}=\left[\frac{(1-\theta)}{\theta} \frac{\left(\bar{\psi}_{1}-\bar{\psi}_{0}\right)}{\bar{\psi}_{0}}\left(\frac{1}{\beta}+\delta-1\right)-\delta\right] K^{* s s} \\
& =\left[\frac{(1-\theta)}{\theta} \frac{\left(\bar{\psi}_{1}-\bar{\psi}_{0}\right)}{\bar{\psi}_{0}}\left(\frac{1}{\beta}+\delta-1\right)-\delta\right]\left[\frac{\theta}{1-\theta} \frac{\bar{\psi}_{0} q^{\bar{s} s}}{\frac{1}{\beta}+\delta-1}\right]^{\frac{1}{1-\theta}} \overline{L^{s s}} \\
& I^{s s}=\delta K^{s s}=\delta\left[\frac{\theta}{1-\theta} \frac{\overline{\psi_{0}} q^{\bar{s} s}}{\frac{1}{\beta}+\delta-1}\right]^{\frac{1}{1-\theta}} L^{-s s} \\
& I^{* s s}=\delta K^{* s s}=\delta\left[\frac{\theta}{1-\theta} \frac{\bar{\psi}_{0} q^{s s}}{\frac{1}{\beta}+\delta-1}\right]^{\frac{1}{1-\theta}} \bar{L}^{-s s} \\
& M^{s s}=\bar{\alpha} D^{s s}+\frac{1-\bar{\alpha}^{2}}{2 \bar{\eta}} Y^{s s} \\
& M^{* s s}=\bar{\alpha} D^{* s s}+\frac{1-\bar{\alpha}^{2}}{2 \bar{\eta}} Y^{* s s} \\
& C^{s s}=Y^{s s}-M^{s s}-I^{s s}-\Phi^{s s}=\left(1-\frac{(1-\bar{\alpha})^{2}}{2 \bar{\eta}}\right) Y^{s s}-M^{s s}-I^{s s} \\
& =\left[\left(1-\frac{(1-\bar{\alpha})^{2}}{2 \bar{\eta}}\right) q^{\bar{s} s}\left[\frac{\theta}{1-\theta} \frac{\overline{\psi_{0}} q_{a}^{\bar{s} s}}{\frac{1}{\beta}+\delta-1}\right]^{\frac{\theta}{1-\theta}}-\left(\delta+\bar{\alpha}\left(\frac{1}{\beta}-1\right)\right)\left[\frac{\theta}{1-\theta} \frac{\overline{\psi_{0}} q^{\bar{s} s}}{\frac{1}{\beta}+\delta-1}\right]^{\frac{1}{1-\theta}}\right] \overline{L^{s s}} \\
& C^{* s s}=Y^{* s s}-M^{* s s}-I^{* s s}-\Phi^{* s s}=\left(1-\frac{(1-\bar{\alpha})^{2}}{2 \bar{\eta}}\right) Y^{* s s}-M^{* s s}-I^{* s s} \\
& =\left[\left(1-\frac{(1-\bar{\alpha})^{2}}{2 \bar{\eta}} q^{\bar{s} s}\left[\frac{\theta}{1-\theta} \frac{\bar{\psi}_{0} q^{\bar{s} s}}{\frac{1}{\beta}+\delta-1}\right]^{\frac{\theta}{1-\theta}}-\left(\delta+\bar{\alpha}\left(\frac{1}{\beta}-1\right)\right)\left[\frac{\theta}{1-\theta} \frac{\bar{\psi}_{0} q^{\bar{s} s}}{\frac{1}{\beta}+\delta-1}\right]^{\frac{1}{1-\theta}}\right] \overline{L^{s s}}\right.
\end{aligned}
$$


The parameters $\eta$ and $\eta^{*}$ are selected such that steady state dividends are positive. In particular with symmetry

$$
\eta=\eta^{*}=\bar{\eta}>\frac{(1-\bar{\alpha})\left\{(1+\bar{\alpha})\left(\frac{1}{\beta}+\delta-1\right)-\theta(1-\bar{\alpha})\left(\frac{1}{\beta}-1\right)\right\}}{2 \bar{\alpha} \theta\left(\frac{1}{\beta}-1\right)}
$$

Other prices are as follows ${ }^{36}$ :

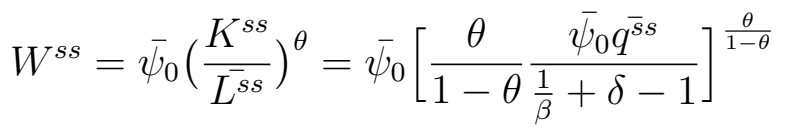

$$
\begin{aligned}
& W^{* s s}=\bar{\psi}_{0}\left(\frac{K^{* s s}}{L^{\overline{s s}}}\right)^{\theta}=\bar{\psi}_{0}\left[\frac{\theta}{1-\theta} \frac{\bar{\psi}_{0} q^{\bar{s} s}}{\frac{1}{\beta}+\delta-1}\right]^{\frac{\theta}{1-\theta}} \\
& P^{s s}=\frac{\beta}{1-\beta} D^{s s}=\frac{\beta}{1-\beta}\left[\frac{(1-\theta)}{\theta} \frac{\left(\bar{\psi}_{1}-\bar{\psi}_{0}\right)}{\bar{\psi}_{0}}\left(\frac{1}{\beta}+\delta-1\right)-\delta\right] K^{s s} \\
& =\frac{\beta}{1-\beta}\left[\frac{(1-\theta)}{\theta} \frac{\left(\bar{\psi}_{1}-\bar{\psi}_{0}\right)}{\bar{\psi}_{0}}\left(\frac{1}{\beta}+\delta-1\right)-\delta\right]\left[\frac{\theta}{1-\theta} \frac{\bar{\psi}_{0} q^{\bar{s} s}}{\frac{1}{\beta}+\delta-1}\right]^{\frac{1}{1-\theta}} L^{\overline{s s}} \\
& P^{* s s}=\frac{\beta}{1-\beta} D^{* s s}=\frac{\beta}{1-\beta}\left[\frac{(1-\theta)}{\theta} \frac{\left(\bar{\psi}_{1}-\bar{\psi}_{0}\right)}{\bar{\psi}_{0}}\left(\frac{1}{\beta}+\delta-1\right)-\delta\right] K^{* s s} \\
& =\frac{\beta}{1-\beta}\left[\frac{(1-\theta)}{\theta} \frac{\left(\bar{\psi}_{1}-\bar{\psi}_{0}\right)}{\bar{\psi}_{0}}\left(\frac{1}{\beta}+\delta-1\right)-\delta\right]\left[\frac{\theta}{1-\theta} \frac{\overline{\psi_{0}} q^{\bar{s} s}}{\frac{1}{\beta}+\delta-1}\right]^{\frac{1}{1-\theta}} L^{-s} \\
& R^{s s}=\frac{1}{\beta}-1 \\
& R^{* s s}=\frac{1}{\beta}-1
\end{aligned}
$$

Of the above prices, $R^{s s}$ and $R^{* s s}$ are independent of the institutional parameters.

\section{B.2.2 The Steady-State with Asymmetric Countries}

As before, the steady-state value of $K^{s s}$ and $K^{* s s}$ can be expressed in terms of $q_{a}^{s s}, q_{a}^{* s s}, q_{b}^{s s}$, and $q_{b}^{* s s}, L^{s s}$ and $L^{* s s}$. From the Euler equations for investment:

$$
\begin{aligned}
K^{s s} & =\left[\frac{\theta}{1-\theta} \frac{\psi_{0} q_{a}^{s s}}{\frac{1}{\beta}+\delta-1}\right]^{\frac{1}{1-\theta}} L^{s s} \\
K^{* s s} & =\left[\frac{\theta}{1-\theta} \frac{\psi_{0}^{*} q_{b}^{* s s}}{\frac{1}{\beta}+\delta-1}\right]^{\frac{1}{1-\theta}} L^{* s s}
\end{aligned}
$$

Note that $K^{s s} \neq K^{* s s}$ because $\psi_{0} \neq \psi_{0}^{*}$. Substituting the expressions for $K^{s s}$ and $K^{* s s}$ in the production function for intermediate goods we get

\footnotetext{
${ }^{36}$ Note that $f^{s s}=\frac{1-\bar{\alpha}}{\bar{\eta}}$ and $f^{* s s}=\frac{1-\bar{\alpha}}{\bar{\eta}}$.
} 


$$
\begin{aligned}
& Y_{a}^{s s}=K^{s s \theta} L^{s s 1-\theta}=\left[\frac{\theta}{1-\theta} \frac{\psi_{0} q_{a}^{s s}}{\frac{1}{\beta}+\delta-1}\right]^{\frac{\theta}{1-\theta}} L^{s s} \\
& Y_{b}^{s s}=K^{* s s \theta} L^{* s s 1-\theta}=\left[\frac{\theta}{1-\theta} \frac{\psi_{0}^{*} q_{b}^{* s s}}{\frac{1}{\beta}+\delta-1}\right]^{\frac{\theta}{1-\theta}} L^{* s s}
\end{aligned}
$$

From the definition of GDP we get

$$
\begin{aligned}
Y^{s s} & =q_{a}^{s s} Y_{a}^{s s}=q_{a}^{s s}\left[\frac{\theta}{1-\theta} \frac{\psi_{0} q_{a}^{s s}}{\frac{1}{\beta}+\delta-1}\right]^{\frac{\theta}{1-\theta}} L^{s s} \\
Y^{* s s} & =q_{b}^{* s s} Y_{b}^{s s}=q_{b}^{* s s}\left[\frac{\theta}{1-\theta} \frac{\psi_{0}^{*} q_{b}^{* s s}}{\frac{1}{\beta}+\delta-1}\right]^{\frac{\theta}{1-\theta}} L^{* s s}
\end{aligned}
$$

When $\left(G(a, b)=a^{\omega} b^{1-\omega}\right)$ we get from the first order conditions for optimal input combinations:

$$
\begin{aligned}
a^{s s} & =\omega Y_{a}^{s s} \\
a^{* s s} & =(1-\omega) Y_{a}^{s s} \\
b^{s s} & =(1-\omega) Y_{b}^{s s} \\
b^{* s s} & =\omega Y_{b}^{s s}
\end{aligned}
$$

Plugging in the optimal intermediate input combinations that go into making final goods and the production function of intermediate good in terms of capital and labor we get from $q_{a}^{s s}=\frac{Y^{s s}}{Y_{a}^{s s}}$ etc., the set of intermediate goods prices for $G(a, b)=a^{\omega} b^{1-\omega}(\sigma=1)$ :

$$
\begin{aligned}
q_{a}^{s s} & =\omega^{\omega}(1-\omega)^{1-\omega}\left(\frac{K^{* s s}}{K^{s s}}\right)^{\theta(1-\omega)} \\
q_{a}^{* s s} & =\omega^{\omega}(1-\omega)^{1-\omega}\left(\frac{K^{* s s}}{K^{s s}}\right)^{\theta \omega} \\
q_{b}^{s s} & =\omega^{\omega}(1-\omega)^{1-\omega}\left(\frac{K^{s s}}{K^{* s s}}\right)^{\theta \omega} \\
q_{b}^{* s s} & =\omega^{\omega}(1-\omega)^{1-\omega}\left(\frac{K^{s s}}{K^{* s s}}\right)^{\theta(1-\omega)} \\
e^{s s} & =\left(\frac{K^{* s s}}{K^{s s}}\right)^{\theta(1-2 \omega)} \\
t^{s s} & =\left(\frac{K^{* s s}}{K^{s s}}\right)^{\theta}
\end{aligned}
$$

Note that when $K^{s s}=K^{* s s}$, the intermediate good prices (and quantities) reduce to the same 
expressions as in the case of symmetric countries because they are functions of the ratio $\frac{K^{s s}}{K^{* s s}}$, with $q_{a}^{s s}=q_{a}^{* s s}=q_{b}^{s s}=q_{b}^{* s s}=\omega^{\omega}(1-\omega)^{1-\omega}$ for the Cobb-Douglas case.

Plugging the relative prices back into the expressions for capital, we have for the Cobb-Douglas case:

$$
\begin{aligned}
K^{s s} & =\zeta_{1}^{\frac{1}{1-\theta}} \psi_{0}^{\frac{1-\theta \omega}{\zeta_{2}}} \psi_{0}^{* \frac{\theta(1-\omega)}{\zeta_{2}}} L^{s s} \\
K^{* s s} & =\zeta_{1}^{\frac{1}{1-\theta}} \psi_{0}^{* \frac{1-\theta \omega}{\zeta_{2}}} \psi_{0}^{\frac{\theta(1-\omega)}{\zeta_{2}}} L^{* s s}
\end{aligned}
$$

where

$$
\begin{aligned}
& \zeta_{1}=\left[\frac{\theta}{1-\theta} \frac{\omega^{\omega}(1-\omega)^{1-\omega}}{\frac{1}{\beta}+\delta-1}\right] \\
& \zeta_{2}=(1-\theta)(1+\theta-2 \omega \theta)
\end{aligned}
$$

and $L^{* s s}=L^{s s}$ by calibration. Note that we can get symmetric countries as a special case of the above, when $\zeta=\zeta^{*}$. From the definition of dividends, the budget constraints of the four agents, and the final goods resource constraint we have

$$
\begin{aligned}
D^{s s} & =\left[\frac{(1-\theta)}{\theta} \frac{\left(\psi_{1}-\psi_{0}\right)}{\psi_{0}}\left(\frac{1}{\beta}+\delta-1\right)-\delta\right] K^{s s} \\
D^{* s s} & =\left[\frac{(1-\theta)}{\theta} \frac{\left(\psi_{1}^{*}-\psi_{0}^{*}\right)}{\psi_{0}^{*}}\left(\frac{1}{\beta}+\delta-1\right)-\delta\right] K^{* s s} \\
I^{s s} & =\delta K^{s s} \\
I^{* s s} & =\delta K^{* s s} \\
M^{s s} & =\alpha D^{s s}+\frac{1-\alpha^{2}}{2 \eta} Y^{s s} \\
M^{* s s} & =\alpha D^{* s s}+\frac{1-\alpha^{* 2}}{2 \eta^{*}} Y^{* s s} \\
C^{s s} & =Y^{s s}-M^{s s}-I^{s s}-\Phi^{s s}=\left(1-\frac{(1-\alpha)^{2}}{2 \eta}\right) Y^{s s}-M^{s s}-I^{s s} \\
C^{* s s} & =Y^{* s s}-M^{* s s}-I^{* s s}-\Phi^{* s s}=\left(1-\frac{\left(1-\alpha^{*}\right)^{2}}{2 \eta^{*}}\right) Y^{* s s}-M^{* s s}-I^{* s s}
\end{aligned}
$$

and the other prices are 


$$
\begin{aligned}
P^{s s} & =\frac{\beta}{1-\beta} D^{s s} \\
P^{* s s} & =\frac{\beta}{1-\beta} D^{* s s} \\
R^{s s} & =\frac{1}{\beta}-1 \\
R^{* s s} & =\frac{1}{\beta}-1 \\
W^{s s} & =\psi_{0}\left(\frac{K^{s s}}{L^{s s}}\right)^{\theta} \\
W^{* s s} & =\psi_{0}^{*}\left(\frac{K^{* s s}}{L^{* s s}}\right)^{\theta}
\end{aligned}
$$

Of the above prices, $R^{s s}$ and $R^{* s s}$ are independent of the institutional parameters, which is utilized in the numerical solution of portfolios when countries are asymmetric.

\section{B.3 Details of Numerical Methods}

This section contains descriptions of the numerical algorithms used in the paper. The procedure followed to compute the steady state portfolios follow Tille and Van Wincoop (2010) and Devereux and Sutherland (2011) closely.

\section{B.3.1 Algorithm for Computing a Numerical Solution for Portfolios}

Following Devereux and Sutherland (2011) we can rewrite the North outsider's budget constraint in terms of the outsider's total financial wealth, the amount of this wealth invested in the the North asset (both in terms of the North consumption good), and the excess returns on the North asset. In terms of the stock prices and equity shares, define financial wealth of the Northern outsider, $\Lambda\left(s^{t}\right)$, as the value of total asset holdings in terms of the North consumption good after history $s^{t}$,

$$
\Lambda\left(s^{t}\right) \equiv P\left(s^{t}\right) \lambda_{N N}\left(s^{t}\right)+e\left(s^{t}\right) P^{*}\left(s^{t}\right) \lambda_{N S}\left(s^{t}\right) \equiv \Lambda_{N N}\left(s^{t}\right)+\Lambda_{N S}\left(s^{t}\right)
$$

where $\Lambda_{N N}$ and $\Lambda_{N S}$ are the amounts of wealth invested in the two assets expressed in terms of the North consumption good, ${ }^{37}$ and asset excess returns as

$$
R_{x}\left(s^{t}\right)=R\left(s^{t}\right)-R^{*}\left(s^{t}\right)
$$

\footnotetext{
${ }^{37}$ The fractions of outsider wealth invested in each asset are defined as $\alpha_{N N}^{o}=\frac{\Lambda_{N N}\left(s^{t}\right)}{\Lambda\left(s^{t}\right)}$ and $\alpha_{N S}^{o}=\frac{\Lambda_{N S}\left(s^{t}\right)}{\Lambda\left(s^{t}\right)}$ respectively.
} 
where $R\left(s^{t}\right) \equiv \frac{P\left(s^{t}\right)+D\left(s^{t}\right)}{P\left(s^{t-1}\right)}$ and $R^{*}\left(s^{t}\right) \equiv \frac{P^{*}\left(s^{t}\right)+D^{*}\left(s^{t}\right)}{P^{*}\left(s^{t-1}\right)}$ are asset returns. The budget constraint of the Northern outsider can then be written as

$$
\Lambda\left(s^{t}\right)=q_{a}\left(s^{t}\right) W\left(s^{t}\right) L\left(s^{t}\right)+\Lambda_{N N}\left(s^{t-1}\right) R_{x}\left(s^{t}\right)+\Lambda_{N S}\left(s^{t-1}\right) \frac{e\left(s^{t}\right)}{e\left(s^{t-1}\right)} R^{*}\left(s^{t}\right)-C\left(s^{t}\right) .
$$

As shown in Devereux and Sutherland (2011), all the variables in the model can be written as functions of the state variable $\Lambda\left(s^{t}\right)$, for example, $\Lambda_{N N}\left(s^{t}\right)=\Lambda_{N N}\left(\Lambda\left(s^{t}\right)\right)$. Each of these in turn can be written as the Taylor series sum of various order terms, for example (suppressing the state notation),

$$
\Lambda_{N N}\left(\Lambda_{t}\right)=\Lambda_{N N}(\bar{\Lambda})+\Lambda_{N N}^{\prime}(\bar{\Lambda})\left(\Lambda_{t}-\bar{\Lambda}\right)+O\left(\epsilon^{2}\right)
$$

Taking second-order expansions of the four Euler equations in our model for additively separable CRRA utility, we get after some algebra ,

$$
E_{t}\left[\gamma\left(\hat{R}_{x, t+1}-\hat{e}_{t+1}\right)\left(\hat{C}_{t+1}^{*}-\hat{C}_{t+1}\right)+\hat{e}_{t+1} \hat{R}_{x, t+1}-\hat{e}_{t+1}^{2}\right]=O\left(\epsilon^{3}\right)
$$

and

$$
E_{t}\left[\hat{R}_{x, t+1}\right]=E_{t}\left[\frac{1}{2}\left(\hat{R}_{t+1}^{* 2}-\hat{R}_{t+1}^{2}\right)+\frac{\gamma}{2}\left(\hat{C}_{t+1}^{*}+\hat{C}_{t+1}\right)\left(\hat{R}_{x, t+1}+\hat{e}_{t+1}\right)+\frac{\gamma}{2} \hat{e}_{t+1}\left(\hat{R}_{t+1}^{*}+\hat{R}_{t+1}\right)\right]
$$

where $\hat{R}_{x, t+1}=\hat{R}_{t+1}-\hat{R}_{t+1}^{*}$. Note here that the model satisfies Property 1 and Property 2 in Devereux and Sutherland (2011) because, (i) the first expression above involves only products, and hence first-order Taylor expansions of the variables are sufficient to evaluate it to the second order, and (ii) the first-order terms of the Taylor expansion of the variables themselves are only functions of the zero-order term of $\Lambda_{N N}$, and hence also of $\lambda_{N N}$ because $\Lambda_{N N}$ enters the model only through the term $\Lambda_{N N}\left(s^{t-1}\right) R_{x}\left(s^{t}\right) \approx \bar{\Lambda}_{N N} \hat{R}_{x}\left(s^{t}\right)$ in the outsiders' budget constraint, where $\bar{\Lambda}_{N N}=\bar{P} \bar{\lambda}_{N N}$. The expressions above are analogous to equations 14 and 15 in Devereux and Sutherland (2011) page 347.

Since Properties 1 and 2 are satisfied, solutions to $\bar{\Lambda}_{N N}$ and $\bar{\Lambda}_{N S}$ (and hence $\bar{\lambda}_{N N}$ and $\bar{\lambda}_{N S}$ ) can be found by evaluating the left hand side of the first expression numerically. The correct solution would involve the left hand side being zero up to a third order approximation error. This fixed-point procedure can be implemented by approximating the model variables required to evaluate the expression up to the first order conditional on values of $\bar{\Lambda}_{N N}$ and $\bar{\Lambda}_{N S}$, because these are functions of the zero-order portfolio only. The precise algorithm followed is as follows:

1. The first step is to find a point around which to approximate the non-portfolio decision rules. 
For the non-portfolio variables, this point is the unique stationary solution to the set of equilibrium conditions of the model (when the scale parameter of the variance of the driving shocks is equal to zero, the non-stochastic steady-state). The steady-state values of all non-portfolio variables are provided in the previous section.

2. Use a 'good' guess for the portfolio variables $\bar{\Lambda}_{N N}$ (and hence $\bar{\Lambda}_{N N}, \bar{\Lambda}_{N S}$ and $\bar{\Lambda}_{N S}$ ). ${ }^{38}$ Having a 'good' guess just makes the procedure faster but any arbitrary guess would also suffice. ${ }^{39}$

3. Around the chosen steady-state, find Taylor series approximation of the optimal dynamics of the control and state variables using the algorithm developed by Schmitt-Grohé and Uribe (2004). Extract only the first-order components of these because as argued above, these depend only on the zero order component of portfolios, which is the object of interest.

4. Evaluate the expression $E_{t}\left[\gamma \hat{R}_{x, t+1}\left(\hat{C}_{t+1}^{*}-\hat{C}_{t+1}\right)-\gamma \hat{e}_{t+1}\left(\hat{C}_{t+1}^{*}-\hat{C}_{t+1}\right)-\hat{e}_{t+1} \hat{R}_{x, t+1}-\hat{e}_{t+1}^{2}\right]$ (whose derivation is described above) using these first-order approximations for non-portfolio variables. Theoretically, this expression should be equal to zero up to a third order approximation error. In practice, if it is less than some small approximation error $\epsilon$ then stop the procedure. ${ }^{40}$ If not, update the guess for $\bar{\Lambda}_{N N}$ and $\bar{\Lambda}_{N S}$ (and hence $\bar{\lambda}_{N N}$ and $\bar{\lambda}_{N S}$ ) and go back to step 2.

Figure B.3.1 shows the value (in logarithms to compress the scale) of the expression above, which I label the "Devereux \& Sutherland-Tille \& Van Wincoop" (DS-TVW henceforth) error, over a fine grid of portfolio shares (the distance between each point on the grid is $10^{-5}$ ) for $\gamma=1.01$. The quantity plotted on the horizontal axis is the share of wealth invested in the foreign asset in a symmetric equilibrium. The zero-order share of wealth devoted to foreign and domestic assets are approximately $6.56 \%$ and $93.44 \%$.

\footnotetext{
${ }^{38}$ To see why this is the case for steady state portfolios, recall that the steady state value of the non-portfolio variables do not depend on the value of the zero order or steady state portfolio. In particular, steady state consumption and labor income do not depend on the zero order portfolio. Thus for any two arbitrary steady-states denoted by 1 and 2 the values of ownership shares must be related by: $\lambda_{N N 1} D^{s s}+\lambda_{N S 1} D^{* s s} e^{s s}=\lambda_{N N 2} D^{s s}+$ $\lambda_{N S 2} D^{* s s} e^{s s}$. In particular $\lambda_{N N} D^{s s}+\lambda_{N S} D^{* s s} e^{s s}=(1-\alpha) D^{s s}$. Using the stock market clearing condition in the foreign country, and the expression for steady-state stock prices, this reduces to $\lambda_{N N} P^{s s}-\lambda_{S S} P^{* s s} e^{s s}=$ $(1-\alpha) P^{s s}-\left(1-\alpha^{*}\right) P^{* s s} e^{s s}$. We can use this condition to pin down $\bar{\lambda}_{N N}, \bar{\lambda}_{N S}$ and $\bar{\lambda}_{N S}$ (and hence $\bar{\Lambda}_{N N}, \bar{\Lambda}_{N S}$, $\left.\bar{\Lambda}_{N S}\right)$ once $\bar{\Lambda}_{N N}$ is found from the simulations.

${ }^{39}$ The simulations use as their starting guess the portfolios in Proposition 2 and then progressively perturb parameters like $\sigma, \gamma$, and $\eta$ to find their effect on portfolios.

${ }^{40} \epsilon$, the stopping criterion, in all the simulations is set to be less than equal to the order of magnitude of the standard deviations of model innovations raised to the third power, or $O\left(\epsilon^{3}\right)$. Note that this is higher than the approximation error predicted for the case where we have analytical solutions because in this case portfolios are constant, so we only have the zero order portfolio without any of the higher order components of the portfolio.
} 


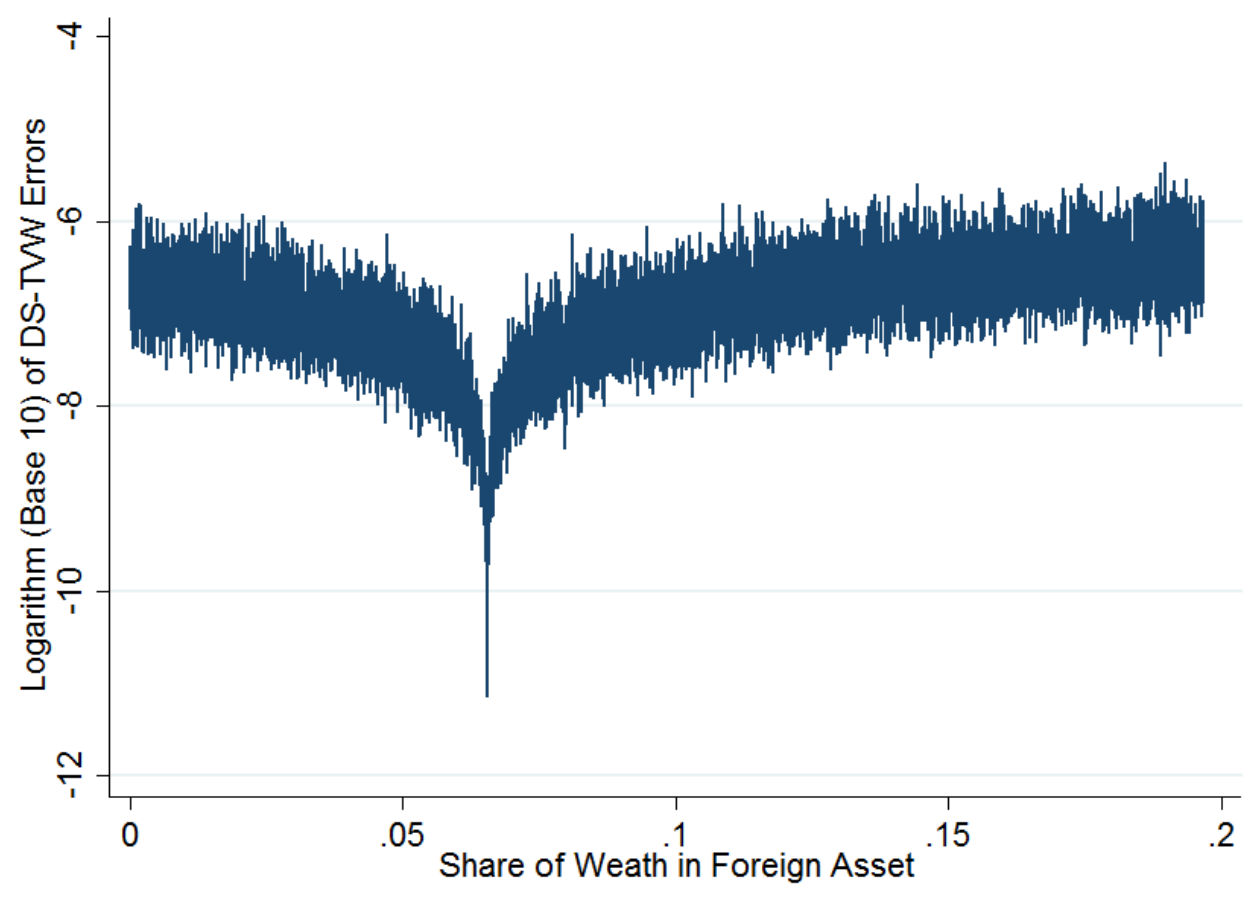

Figure 8: ERRORS IN THE EULER EQUATION CONDITIONS.

Notes: The x-axis shows portfolio shares and the y-axis shows the error in the Euler equation conditions.

\section{B.3.2 Algorithm for Insider's Choice of Ownership for Given $\eta$ and $\eta^{*}$}

We are seeking a maximum of the function $V$ (described in the body of the paper) that maps insider ownership in the South, $\alpha^{*}$, to expected lifetime utility of the Southern insider. Note that $\alpha^{*} \in \mathcal{R}$, and that we only seek a local maximum within a small interval of $\mathcal{R}$, namely $\left[\alpha_{\min }^{*}, \alpha_{\max }^{*}\right]$, given by the setup of the problem. Specifically, $\alpha_{\min }^{*} \geq 0$ and $\alpha_{\max }^{*} \leq \alpha_{i,-1}^{*}$, where $\alpha_{i,-1}^{*}$ is the initial insider ownership in the South, since the insider cannot short sell or borrow.

1. Outer loop A: Start with the initial distribution of ownership $\alpha_{i,-1}^{*}$ in the South and $\alpha$ in the North, the latter being fixed. Fix the interval within which to conduct the search for the best $\alpha^{*}$ as $\left[0, \alpha_{i,-1}^{*}\right]$. Northern stock ownership of Southern insider is given by the budget constraint $\alpha_{S N}=\frac{e^{s s} P^{* s s}\left(\alpha^{*}\right)}{P^{s s}(\alpha)}\left(\alpha^{*}-1-\alpha^{*}\right)$ for $\alpha^{*} \in\left[0, \alpha_{i,-1}^{*}\right]$.

2. Inner loop: Approximate optimal decision rules of the economy, including for outsider portfolios, around the steady-state for the value of $\alpha^{*}$ supplied by the outer loop. The output of the inner loop will be the equilibrium decision rules for all variables of the economy, with insider ownerships $\alpha^{*}$ and $\alpha$ in the South and North respectively.

3. Outer loop B: Simulate economy for 100 periods with decision rules from inner loop, 
calculate discounted sum of insider utility over these 100 periods and take average over 50 simulations, and store. Update $\alpha^{*}$ to a new value and go back to step 1.

4. After the outer loop has cycled through the grid of values $\alpha^{*} \in\left[0, \alpha_{i,-1}^{*}\right]$, select the $\alpha^{*}$ with the highest discounted sum of simulated utility as the equilibrium insider ownership in the South. 